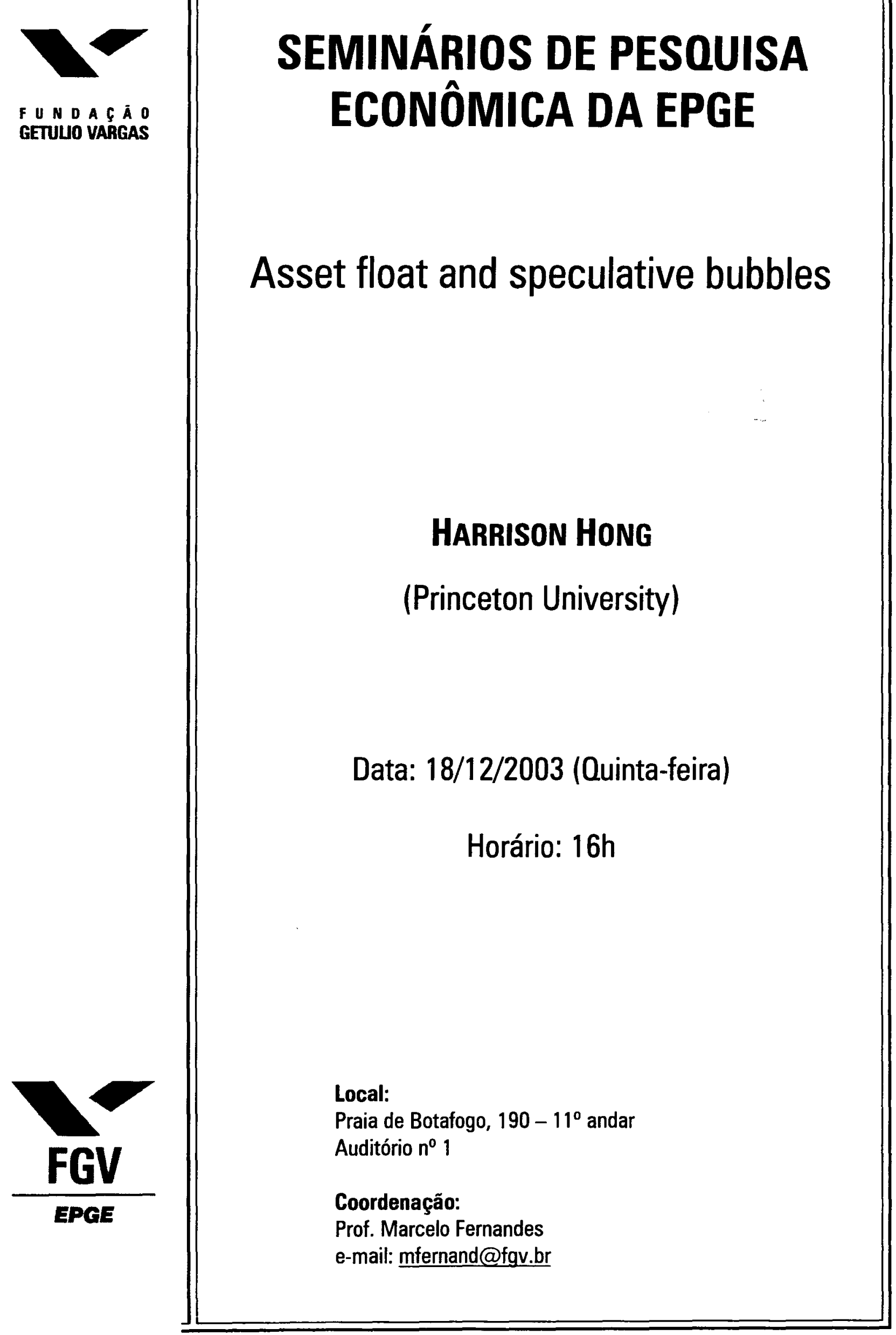




\title{
Asset Float and Speculative Bubbles
}

\author{
Harrison Hong, José Scheinkman, and Wei Xiong* \\ Princeton University
}

October 20,2003

\begin{abstract}
We model the relationship between float (the tradeable shares of an asset) and stock price bubbles. Investors trade a stock that initially has a limited float because of insider lock-up restrictions but the tradeable shares of which increase over time as these restrictions expire. A speculative bubble arises because investors, with heterogeneous beliefs due to overconfidence and facing short-sales constraints, anticipate the option to resell the stock to buyers with even higher valuations. With limited risk absorption capacity, this resale option depends on float as investors anticipate the change in asset supply over time and speculate over the degree of insider selling. Our model yields implications consistent with the behavior of internet stock prices during the late nineties, such as the bubble, share turnover and volatility decreasing with float and stock prices tending to drop on the lock-up expiration date though it is known to all in advance.
\end{abstract}

* We thank the National Science Foundation for financial support. We also thank seminar participants at the University of Iowa for their comments. Please address inquiries to Wei Xiong, 26 Prospect Avenue, Princeton, NJ 08540, wxiong@princeton.edu. 


\section{Introduction}

The rise and fall of internet stock prices during the late nineties was extraordinary, even given the volatile history of speculative markets. As is well documented, during the twoyear period from 1998 to early 2000, the public equity of the internet sector earned a return of over $1000 \%$. By February of 2000, this largely profitless sector of roughly four-hundred companies commanded valuations that represented six percent of the market capitalization and accounted for $20 \%$ of the publicly traded volume of the U.S. stock market (see, e.g., Ofek and Richardson (2003)). The average price-to-earnings ratio of these companies hovered around 856. And the relative valuations of equity carveouts like Palm $/ 3 \mathrm{Com}$ suggested that internet valuations were detached from fundamental value (see, e.g., Lamont and Thaler (2003), Mitchell, Pulvino, and Stafford (2002)). These figures led many to believe that this set of stocks was in the midst of an asset price bubble. This bubble bursted in the spring of 2000 and by the end of the same year, these companies' valuations had returned to pre-1998 levels, losing nearly $70 \%$ from the peak and trading volume and return volatility also largely dried up in the process.

Many observers suspect that a key to explaining the rise and fall of internet stock prices lies in understanding the effect of the limited float (the publicly tradeable shares) of these companies on their prices. Since many internet companies were recent initial public offerings (IPO), they typically had $80 \%$ of their shares locked up-the shares held by insiders and other pre-IPO equity holders are not tradeable for at least six months after the IPO date. In comparison to other firms, these companies had a very limited float. ${ }^{1}$ As a result, it may have been difficult to borrow the shares needed to short these companies, thereby allowing any mis-pricing to persist. Importantly, Ofek and Richardson (2003) document that the bursting of the bubble in early 2000 coincided with a dramatic increase in the float of the internet sector as the lock-ups of many of these stocks expired: from the beginning of

\footnotetext{
${ }^{1}$ In recent years, it has become standard for some $80 \%$ of the shares of IPOs to be locked up for about six months. Economic rationales for lock-ups include a commitment device to alleviate moral hazard problems, to signal firm quality, or rent extraction by underwriters.
} 
November 1999 to the end of April 2000, the value of unlocked shares due to insider selling rose from 70 billion dollars to over 270 billion dollars. A reasonable conjecture might be that when the internet float increased, it became much easier to short-sell these companies, thereby allowing rational arbitrageurs to finally bring an end to the bubble. Needless to say, there has been little formal analysis of this issue despite such provocative speculations. ${ }^{2}$

In this paper, we attempt to understand the relationship between float and stock price bubbles. Our analysis builds on early work regarding the formation of speculative bubbles due to the combined effects of heterogeneous beliefs (i.e. agents agreeing to disagree) and short-sales constraints (see, e.g., Miller (1977), Harrison and Kreps (1978), Chen, Hong and Stein (2002) and Scheinkman and Xiong (2003)). In particular, we follow Scheinkman and Xiong (2003) in assuming that overconfidence-the belief of an agent that his information is more accurate than what it is-is the source of disagreement. Although there are many different ways to generate heterogeneous beliefs, a large literature in psychology strongly indicates that overconfidence is a pervasive aspect of human behavior and this assumption allows for a tractable model. In addition, the assumption that investors face short-sales constraints is also eminently plausible since even most institutional investors such as mutual funds do not short. ${ }^{3}$

More specifically, we consider a discrete-time, multi-period model in which investors trade a stock that initially has a limited float because of lock-up restrictions but the tradeable shares of which increase over time as insiders become free to sell their positions. We assume that there is limited risk absorption capacity (i.e. downward sloping demand curve) for the stock. This assumption is meant to capture the fact that many of those who traded internet stocks were individuals who were undoubtedly undiversified and that there are other frictions

\footnotetext{
${ }^{2}$ For other hypotheses on why float may matter for asset prices, see Cochrane (2003).

${ }^{3}$ Roughly $70 \%$ of mutual funds explicitly state (in Form N-SAR that they file with the SEC) that they are not permitted to sell short (see Almazan, Brown, Carlson and Chapman (1999)). Seventy-nine percent of equity mutual funds make no use of derivatives whatsoever (either futures or options), suggesting that funds are also not finding synthetic ways to take short positions (see Koski and Pontiff (1999)). These figures indicate the vast majority of funds never take short positions.
} 
which limit arbitrage. ${ }^{4}$ Moreover, investors receive publicly available signals about terminal payoffs; however, they are divided into two groups and differ in their interpretation of the signals. Since each group overestimates the informativeness of a different signal, they have distinct forecasts of future payoffs. As information flows into the market, their forecasts change and the group that is relatively more optimistic at one point in time may become at a later date relatively more pessimistic. These fluctuations in expectations generate trade. Insiders observe all the signals and rationally process them in deciding how much to sell on the lock-up expiration date. Importantly, investors anticipate changes in asset supply over time due to potential insider selling.

When investors have heterogeneous beliefs due to overconfidence and are short-sales constrained, they pay prices that exceed their own valuation of future dividends as they anticipate finding a buyer willing to pay even more in the future. The price of an asset exceeds fundamental value by the value of this resale option; as a result, there is a bubble component in asset prices. ${ }^{5}$ When there is limited risk absorption capacity, the two groups naturally want to share the risk of holding the supply of the asset. Hence they are unwilling hold all of the tradeable shares without a substantial risk discount. A larger float or a lower risk absorption capacity means that it takes a greater divergence in opinion in the future for an asset buyer to resell the shares, which means the less valuable the resale option is today. So, ex ante, agents are less willing to pay a price above their assessments of fundamentals and the smaller is the bubble. Indeed, we show that the strike price of the resale option depends on the relative magnitudes of asset float to risk absorption capacity-the greater is this ratio, the higher the strike price for the resale option to be in the money.

Since the demand curve for the stock is downward sloping, price naturally declines with supply even in the absence of speculative trading. But when there is speculative trading, price becomes even more sensitive to asset float-i.e. overconfidence leads to a multiplier

\footnotetext{
${ }^{4}$ For instance, Ofek and Richardson (2003) report that the median holding of institutional investors in internet stocks was $25.9 \%$ compared to $40.2 \%$ for non-internet stocks. For internet IPO's, the comparable numbers are $7.4 \%$ to $15.1 \%$. See Shleifer and Vishny (1997) for a description for various limits of arbitrage.

${ }^{5}$ This is the key insight of Harrison and Kreps (1978) and Scheinkman and Xiong (2003).
} 
effect. This multiplier effect is highly nonlinear - it is much bigger when the ratio of float to risk bearing capacity is small than when it is large. Furthermore, since trading volume and share return volatility are tied to the amount of speculative trading, these two quantities also decrease with the ratio of asset float to risk absorption capacity. As a result, our model predicts that a decrease in price associated with greater asset supply is accompanied by lower turnover and return volatility. These auxiliary effects related to turnover and volatility are absent from standard models of asset pricing with downward sloping demand curves.

Importantly, the very event of potential insider selling at the end of the lock-up period leads to a larger bubble than would have otherwise occurred. Since investors are overconfdent, each group essentially thinks that they are smarter than the other group. A natural question that arises is how they view insiders and how insiders process information about fundamentals. Since insiders are typically thought of as having more knowledge about their company than outsiders, it seems natural to assume that each group of investors thinks that the insiders are "smart" like them (i.e. sharing their expectations as opposed to the other group's). Indeed, we assume that they agree to disagree about this proposition. As a result, each group of investors expects the other group to be more aggressive in taking positions in the future when the other group has a higher valuation. The reason is that the other group expects that the insiders will eventually come in and share the risk of their positions with them. Since agents are more aggressive in taking on speculative positions, the resale option and hence the bubble is larger. Just as long as insiders are not infinitely risk averse and they decide how to sell their positions based on their belief about fundamentals, this effect will be present.

As a result, one of the main testable implications of our model is that even controlling for asset supply and risk bearing capacity, a stock in which there is the potential for insider selling will have a larger bubble. Presumably stocks with little float to begin with are the ones that are the most likely to have this potential. Therefore, our model predicts that in the cross-section, stocks with less float, even controlling for firm size, will have a larger 
speculative bubble component and hence a lower expected return.

Using these results, it is easy to see that our theory yields a number of predictions that are consistent with stylized facts regarding the behavior of internet stocks during the late nineties. One of the most striking of these stylized facts is that the internet bubble bursted in the Spring of 2000 when the float of the internet sector dramatically increased. More interestingly from our perspective is that trading volume and return volatility also dried up in the process. Our model can rationalize these stylized facts for a couple of reasons. First, to the extent that the risk absorption capacity in the internet sector stayed the same but the asset supply increased, our model predicts that it requires a bigger divergence of opinion to sustain the bubble, leading to a smaller bubble and less trading volume and volatility. Second, after the expiration of lock-up restrictions, speculation regarding the degree of insider selling also diminished, again leading to a smaller internet bubble.

Interestingly, a bubble bursts with an expansion of asset supply in our model without any change in the cost of short-selling. We think this is one of the virtues of this model, for while short-selling costs are lower for stocks with higher float, empirical evidence indicates that it is difficult to tie the decline in internet valuations in the Spring of 2000 merely to a relaxation of short-sales constraints. ${ }^{6}$ Moreover, a relaxation of short-sales-constraints story cannot easily explain why trading volume and return volatility also dried up after the bubble bursted.

Another outstanding stylized fact regarding internet stocks during the late nineties involve price dynamics across the lock-up expiration date. Empirical evidence suggests that on this date, stock prices tend to decline though the day of the event is known to all in advance. $^{7}$ Our model is able to rationalize this finding. Since investors are overconfident and incorrectly believe that the insiders share their beliefs, to the extent that the insiders' belief is rational (i.e. properly weighing the two public signals) and some investors are more

\footnotetext{
${ }^{6}$ See Ofek and Richardson (2003). Indeed, it is difficult to account for differences, at a given point in time, in the valuations of the internet sector and their non-internet counterpart to differences in the cost-of-short-selling alone.

${ }^{7}$ See Brav and Gompers (2003), Field and Hanka (2001) and Ofek and Richardson (2000).
} 
optimistic than insiders, there will be more selling on the part of insiders on the date of lock-up expiration than is anticipated by outside investors. Hence, the stock price tends to fall on this date.

Our paper proceeds as follows. In Section 2, we review related literature and highlight some of the contributions of our model. A simple version of the model without insider selling is described in Section 3. We present the solution for the general model with insider selling and time varying float in Section 4. We provide further discussions in Section 5 and conclude in Section 6. All proofs are in the Appendix.

\section{Related Literature}

There is a large literature on the effects of heterogeneous beliefs on asset prices and trading volume. Miller (1977) and Chen, Hong and Stein (2002) analyze the overvaluation generated by heterogeneous beliefs. Thse models are static and hence cannot generate an option value related to the dynamics of trading as in our model. Harris and Raviv (1993), Kandel and Pearson (1995), and Kyle and Lin (2002) study models where trading is generated by heterogeneous beliefs. Hong and Stein (2003) consider a model in which heterogeneous beliefs and short-sales constraints lead to market crashes. Harrison and Kreps (1978), Morris (1996) and Scheinkman and Xiong (2003) develop models in which there is a speculative component to asset prices. However, the agents in all these models are risk-neutral, and so float has no effect on prices.

Many studies from psychology find that people overestimate the precision of their knowledge in a number of circumstances, especially for challenging judgment tasks (see Alpert and Raiffa (1982) or Lichtenstein, Fischhoff, and Phillips (1982)). Indeed, even experts can display overconfidence (see Camerer (1995)). A phenomenon related to overconfidence is the "illusion of knowledge" - people who do not agree become more polarized when given arguments that serve both sides (see Lord, Ross and Lepper (1979)). ${ }^{8}$

\footnotetext{
${ }^{8}$ See Hirshleifer (2001) and Barber and Odean (2002) for reviews of this literature.
} 
Motivated by research in psychology, researchers in finance have developed models to analyze the implications of overconfidence on financial markets (see, e.g., Kyle and Wang (1997), Odean (1998), Daniel, Hirshleifer and Subrahmanyam (1998) and Bernardo and Welch (2001).) In these finance papers, overconfidence is typically modelled as overestimation of the precision of one's information. We follow a similar approach, but highlight the speculative motive generated by overconfidence.

The bubble in our model, based on the recursive expectations of traders to take advantage of mistakes by others, is different from "rational bubbles". 9 In contrast to our set up, rational-bubble models are incapable of connecting bubbles with asset float. In addition, in these models, assets must have (potentially) infinite maturity to generate bubbles. Other mechanisms have been proposed to generate asset price bubbles (see, e.g., Allen and Gorton (1993), Allen, Morris, and Postlewaite (1993), and Duffie, Garleanu, and Pedersen (2002)). None of these models emphasize the joint properties of price bubbles and asset float observed in historical episodes.

\section{A Simple Model without Insider Selling}

We begin by providing a simple version of our model without any insider selling. This special case helps develop the intuition for how the relative magnitudes of the supply of tradeable shares and investors' risk-absorption capacity affect a speculative bubble. Below, this version is extended to allow for time-varying float due to the expiration of insider lock-up restrictions.

We consider a single traded asset, which might represent a stock, a portfolio of stocks such as the internet sector, or the market as a whole. There are three dates, $t=0,1,2$. The asset pays off $\tilde{f}$ at $t=2$, where $\tilde{f}$ is normally distributed. A total of $Q$ shares of the asset are outstanding. For simplicity, the interest rate is set to zero.

Two groups of investors, $\mathrm{A}$ and $\mathrm{B}$, trade the asset at $t=0$ and $t=1$. Investors within

\footnotetext{
${ }^{9}$ See Blanchard and Watson (1982) or Santos and Woodford (1997).
} 
each group are identical. They maximize a per-period objective of the following form:

$$
\mathrm{E}[W]-\frac{1}{2 \eta} \operatorname{Var}[W]
$$

where $\eta$ is the risk-bearing capacity of each group. In order to obtain closed-form solutions, we need to use these (myopic) preferences so as to abstract away from dynamic hedging considerations. While unappetizing, it will become clear from our analysis that our results are unlikely to change qualitatively when we admit dynamic hedging possibilities. We further assume that there is limited risk absorption capacity in the stock. ${ }^{10}$

At $t=0$, the two groups of investors have the same prior about $\tilde{f}$, which is normally distributed, denoted by $N\left(\hat{f}_{0}, \tau_{0}\right)$, where $\hat{f}_{0}$ and $\tau_{0}$ are the mean and precision of the belief, respectively. At $t=1$, they receive two public signals:

$$
s_{f}^{A}=\tilde{f}+\epsilon_{f}^{A}, \quad s_{f}^{B}=\tilde{f}+\epsilon_{f}^{B},
$$

where $\epsilon_{f}^{A}$ and $\epsilon_{f}^{B}$ are noises in the signals. The noises are independent and normally distributed, denoted by $N\left(0, \tau_{\epsilon}\right)$, where $\tau_{\epsilon}$ is the precision of the two signals. Due to overconfidence, group A over-estimates the precision of signal $\mathrm{A}$ as $\phi \tau_{\epsilon}$, where $\phi$ is a constant parameter larger than one. In contrast, group B over-estimates the precision of signal B as $\phi \tau_{\epsilon}$.

We first solve for the beliefs of the two groups at $t=1$. Using standard Bayesian updating formulas, they are easily characterized in the following lemma.

Lemma 1 The beliefs of the two groups of investors at $t=1$ are normally distributed, denoted by $N\left(\hat{f}_{1}^{A}, \tau\right)$ and $N\left(\hat{f}_{1}^{B}, \tau\right)$, where the precision is given by

$$
\tau=\tau_{0}+(1+\phi) \tau_{\epsilon}
$$

and the means are given by

$$
\begin{aligned}
& \hat{f}_{1}^{A}=\hat{f}_{0}+\frac{\phi \tau_{\epsilon}}{\tau}\left(s_{f}^{A}-\hat{f}_{0}\right)+\frac{\tau_{\epsilon}}{\tau}\left(s_{f}^{B}-\hat{f}_{0}\right), \\
& \hat{f}_{1}^{B}=\hat{f}_{0}+\frac{\tau_{\epsilon}}{\tau}\left(s_{f}^{A}-\hat{f}_{0}\right)+\frac{\phi \tau_{\epsilon}}{\tau}\left(s_{f}^{B}-\hat{f}_{0}\right) .
\end{aligned}
$$

\footnotetext{
${ }^{10}$ In other words, the asset demand curve is downward sloping. This is meant to simultaneously capture the undiversified positions of individual investors and frictions that limits arbitrage among institutional investors.
} 
Even though the investors share the same prior about the terminal asset payoff and receive the same two public signals, the assumption that they place too much weight on different signals leads to a divergence in their beliefs. Their expectations converge in the limit as $\phi$ approaches one.

Given the forecasts in Lemma 1, we proceed to solve for the equilibrium holdings and price at $t=1$. With mean-variance preferences and short-sales constraints, it is easy to show that, given the price $p_{1}$, the demands of investors $\left(x_{1}^{A}, x_{1}^{B}\right)$ for the asset are

$$
x_{1}^{A}=\max \left[\eta \tau\left(\hat{f}_{1}^{A}-p_{1}\right), 0\right], \quad x_{1}^{B}=\max \left[\eta \tau\left(\hat{f}_{1}^{B}-p_{1}\right), 0\right]
$$

Consider the demand of the group A investors. Since they have mean-variance preferences, their demand for the asset without short-sales constraints is simply $\eta \tau\left(\hat{f}_{1}^{A}-p_{1}\right)$. When their beliefs are less than the market price, they would ideally want to short the asset. Since they cannot, they simply sit out of the market and submit a demand of zero. The intuition for B's demand is similar.

Imposing the market clearing condition, $x_{1}^{A}+x_{1}^{B}=Q$, gives us the following lemma:

Lemma 2 Let $l_{1}=\hat{f}_{1}^{A}-\hat{f}_{1}^{B}$ be the difference in opinion between the investors in groups $A$ and $B$ at $t=1$. The solution for the stock holdings and price on this date are given by the following three cases:

- Case 1: If $l_{1}>\frac{Q}{\eta \tau}$,

$$
x_{1}^{A}=Q, \quad x_{1}^{B}=0, \quad p_{1}=\hat{f}_{1}^{A}-\frac{Q}{\eta \tau} .
$$

- Case 2: If $\left|l_{1}\right| \leq \frac{Q}{\eta \tau}$,

$$
x_{1}^{A}=\eta \tau\left(\frac{l_{1}}{2}+\frac{Q}{2 \eta \tau}\right), \quad x_{1}^{B}=\eta \tau\left(\frac{-l_{1}}{2}+\frac{Q}{2 \eta \tau}\right), \quad p_{1}=\frac{\hat{f}_{1}^{A}+\hat{f}_{1}^{B}}{2}-\frac{Q}{2 \eta \tau} .
$$


- Case 3: If $l_{1}<-\frac{Q}{\eta_{\tau}}$,

$$
x_{1}^{A}=0, \quad x_{1}^{B}=Q, \quad p_{1}=\hat{f}_{1}^{B}-\frac{Q}{\eta \tau} .
$$

Since the investors are risk-averse, they naturally want to share the risks of holding the $Q$ shares of the asset. So, unless their opinions are dramatically different, both groups of investors will be long the asset. This is the situation described in Case 2. In this case, the asset price is determined by the average belief of the two groups, and the risk premium $\frac{Q}{2 \eta \tau}$ is determined by the total risk-bearing capacity. When group A's valuation is significantly greater than that of B's (as in Case 1), investors in group A hold all $Q$ shares, and those in $\mathrm{B}$ sit out of the market. As a result, the asset price is determined purely by group A's opinion, $\hat{f}_{1}^{A}$, adjusted for a risk discount, $\frac{Q}{\eta \tau}$, reflecting the fact that this one group is bearing all the risks of the $Q$ shares. The situation in Case 3 is symmetric to that of Case 1 except that group B's valuation is greater than that of A's.

We next solve for the equilibrium at $t=0$. Given investors' mean-variance preferences, the demand of the agents at $t=0$ are given by

$$
x_{0}^{A}=\max \left[\frac{\eta\left(\mathrm{E}_{0}^{A} p_{1}-p_{0}\right)}{\Sigma^{A}}, 0\right], \quad x_{0}^{B}=\max \left[\frac{\eta\left(\mathrm{E}_{0}^{B} p_{1}-p_{0}\right)}{\Sigma^{B}}, 0\right],
$$

where $\Sigma^{A}$ and $\Sigma^{B}$ are the next-period price change variances under group-A and group-B investors' beliefs:

$$
\Sigma^{A}=\operatorname{Var} r_{0}^{A}\left[p_{1}-p_{0}\right], \quad \Sigma^{B}=\operatorname{Var} r_{0}^{B}\left[p_{1}-p_{0}\right]
$$

Since investors in group A and group B have the same prior, $\Sigma^{A}$ equals $\Sigma^{B}$. We denote them as $\Sigma$. (Moreover, note that $E_{0}^{A}\left[p_{1}\right]=E_{0}^{B}\left[p_{1}\right]$ as well.) It then follows that when we impose the market clearing condition at $t=0, x_{0}^{A}+x_{0}^{B}=Q$, the equilibrium price at $t=0$ is

$$
p_{0}=\frac{1}{2}\left(\mathrm{E}_{0}^{A}\left[p_{1}\right]+E_{0}^{B}\left[p_{1}\right]\right)-\frac{\Sigma}{2 \eta} Q
$$




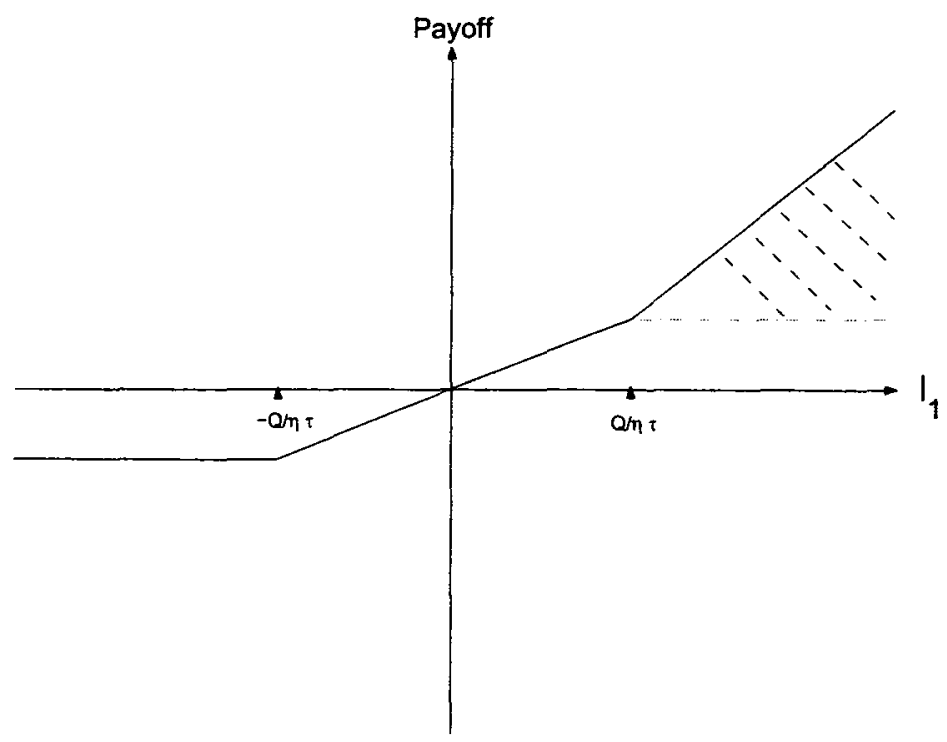

Figure 1: The payoff from the resale option

The key to understanding this price is to evaluate the expectation of $p_{1}$ at $t=0$ under either of the investors' beliefs (since they will also be the same, we will calculate $\mathrm{E}_{0}^{B}\left[p_{1}\right]$ without loss of generality). To do this, it is helpful to re-write the equilibrium price from Lemma 2 (equations (7)-(9)) in the following form:

$$
p_{1}=f_{1}^{B}-\frac{Q}{2 \eta \tau}+ \begin{cases}-\frac{Q}{2 \eta \tau} & \text { if } l_{1}<-\frac{Q}{\eta \tau} \\ \frac{1}{2} l_{1} & \text { if }-\frac{Q}{\eta \tau}<l_{1}<\frac{Q}{\eta \tau}, \\ l_{1}-\frac{Q}{2 \eta \tau} & \text { if } \frac{Q}{\eta \tau}<l_{1}\end{cases}
$$

where $l_{1}=\hat{f}_{1}^{A}-\hat{f}_{1}^{B}$. From Lemma 1 , it is easy to show that

$$
l_{1}=\frac{(\phi-1) \tau_{\epsilon}}{\tau}\left(\epsilon_{f}^{A}-\epsilon_{f}^{B}\right)
$$

So $l_{1}$ has a Gaussian distribution with a mean of zero and a variance of

$$
\sigma_{l}^{2}=\frac{(\phi-1)^{2}(\phi+1) \tau_{\epsilon}}{\phi\left[\tau_{0}+(1+\phi) \tau_{\epsilon}\right]^{2}}
$$

under the beliefs of either group B (or A) agents.

For the expectation of B-investors at $t=0$, there are two uncertain terms in equation (13), $\hat{f}_{1}^{B}$ and a three-piece function of the difference in beliefs $l_{1}$. This three-piece function 
is shown as the solid line in Figure 1. The expectation of $\hat{f}_{1}^{B}$ at $t=0$ is simply $\hat{f}_{0}$. This is simply the investors' valuation for the asset if they were not allowed to sell their shares at $t=1$. The three-piece function represents the value from being able to trade at $t=1$. Calculating its expectation amounts to integrating the area between the solid line and the horizontal axis (in Figure 1) while weighting by the probability density of $l_{1}$. Since the difference in beliefs $l_{1}$ has a symmetric distribution around zero, this expectation is simply determined by the shaded area, which naturally is positive in value.

Intuitively, with differences of opinion and short-sales constraints, the possibility of selling shares when other investors have higher beliefs provides a resale option to the asset owners (see Harrison and Kreps (1978) and Scheinkman and Xiong (2003)). If $\phi=1$, the possibility does not exist. Otherwise, the payoff from the resale option depends on the potential deviation of A-investors' belief from that of B-investors. Following the same logic, we can also derive a similar resale option value for A-investors.

The following theorem summarizes the expectation of A- and B-investors at $t=0$ and the resulting asset price.

Theorem 1 At $t=0$, the conditional expectation of A-investors and B-investors regarding $p_{1}$ are identical:

$$
\mathrm{E}_{0}^{A}\left[p_{1}\right]=\mathrm{E}_{0}^{B}\left[p_{1}\right]=\hat{f}_{0}-\frac{Q}{2 \eta \tau}+\mathrm{E}\left[\left(l_{1}-\frac{Q}{\eta \tau}\right) I_{\left\{l_{1}>\frac{Q}{\eta \tau}\right\}}\right] .
$$

Then, the price at time 0 is

$$
p_{0}=\hat{f}_{0}-\frac{\Sigma}{2 \eta} Q-\frac{Q}{2 \eta \tau}+\mathrm{E}\left[\left(l_{1}-\frac{Q}{\eta \tau}\right) I_{\left\{l_{1}>\frac{Q}{\eta \tau}\right\}}\right] .
$$

There are four parts in the price. The first part, $\hat{f}_{0}$, is the expected value of the fundamental of the asset. The second term, $\frac{\Sigma}{2 \eta} Q$, equals the risk premium for holding the asset from $t=0$ to $t=1$. The third part, $\frac{Q}{2 \eta \tau}$, represents the risk premium for holding the asset 
from $t=1$ to $t=2$. The last term

$$
B(Q)=\mathrm{E}\left[\left(l_{1}-\frac{Q}{\eta \tau}\right) I_{\left\{l_{1}>\frac{Q}{\eta \tau}\right\}}\right]
$$

represents the option value from selling the asset to investors in the other group when they have higher beliefs (the shaded area shown in Figure 1). Its format is similar to a call option with a strike price of $\frac{Q}{\eta \tau}$. Therefore, an increase in $Q$ or a decrease in $\eta$ would raise the strike price of the resale option, and will dramatically reduce the option value.

More formally, we show in the following proposition:

Proposition 1 The size of the bubble decreases with the relative magnitudes of supply $Q$ to risk absorption capacity $\eta$, and increases with the overconfidence parameter $\phi$.

Intuitively, when agents are risk averse, the two groups naturally want to share the risk of holding the shares of the asset. Hence they are unwilling hold the float without a substantial price discount. A larger float means that it takes a greater divergence in opinion in the future for an asset buyer to resell the shares, which means the less valuable the resale option is today. So, ex ante, agents are less willing to pay a price above their assessments of fundamentals and the smaller is the bubble.

Since there is limited risk absorption capacity, price naturally declines with supply even in the absence of speculative trading. But when there is speculative trading, price becomes even more sensitive to asset supply-i.e. a multiplier effect arises. To see this, consider two firms with the same share price, except that one's price is determined entirely by fundamentals whereas the other includes a speculative bubble component as described above. The firm with a bubble component has a smaller fundamental value than the firm without to give them the same share price. We show that the price elasticity of the firm with a speculative bubble to supply is greater than the otherwise comparable firm without a bubble. This multiplier effect is highly nonlinear-it is much bigger when the ratio of supply to risk bearing capacity is small than when it is large. The reason follows from the fact that the 
strike price of the resale option is proportional to $Q$. These results are formally stated in the following proposition:

Proposition 2 Consider two otherwise comparable stocks with the same share price, except that one's value includes a bubble component whereas the other does not. The elasticity of price to supply for the stock with a speculative bubble is greater than the otherwise comparable stock. The difference in these elasticities is given by $B^{\prime}(Q)$. This difference peaks when $Q=0$ (at a value of $\frac{1}{2 \eta \tau}$ ) and monotonically diminishes when $Q$ becomes large.

Moreover, since trading volume and share return volatility are tied to the amount of speculative trading, these two quantities also decrease with the ratio of asset float to risk absorption capacity.

Proposition 3 The expected turnover rate from $t=0$ to $t=1$ decreases with the ratio of supply $Q$ to risk-bearing capacity $\eta$ and increases with $\phi$. Return volatility from $t=0$ to $t=1$ decreases with the ratio of supply $Q$ to risk-bearing capacity.

To see why expected share turnover decreases with $Q$, consider the expected share turnover from $t=0$ to $t=1$. At $t=0$, both groups share the same belief regarding fundamentals and both hold one-half of the shares of the float. (This is also what one expects on average since both groups of investors' prior beliefs about fundamentals is identical.) The maximum share turnover from this period to the next is for one group to become much more optimistic and end up holding all the shares-this would yield a turnover ratio of one-half. But the larger is the float, the greater a divergence of opinion it will take for the optimistic group to hold all the shares tomorrow and therefore the lower is average share turnover.

The intuition for return volatility is similar. Imagine that the two groups of investors have the same prior belief at $t=0$ and each holds one-half of the shares of the float. Next period, if one group buys all the shares from the other, the stock's price depends only on the 
optimists' belief. In contrast, if both groups are still in the market, then the price depends on the average of the two groups' beliefs. Since the variance of the average of the two beliefs is less than the variance of a single group's belief alone, it follows that the greater the float, the less likely it will be for one group to hold all the shares and hence the lower is price volatility.

\section{A Model with Insider Selling and Time-Varying Float}

\subsection{Set-up}

We now extend the simple model of the previous section to allow for time-varying float due to insider selling. Investors trade an asset that initially has a limited float because of lock-up restrictions but the tradeable shares of which increase over time as insiders become free to sell their positions. In practice, the lock-up period lasts around six months after a firm's initial public offering date. During this period, most of the shares of the company are not tradeable by the general public. The lock-up expiration date (the date when insiders are free to trade their shares) is known to all in advance.

The model has a total of eight periods. The timeline is described in Figure 2. There are three stages to our model, Stages I, II and III, which are meant to qualitatively capture the imposition and subsequent expiration of restrictions on insider selling. The first two periods belong to Stage I and are denoted by $(I, 0)$ and $(I, 1)$. Stage I corresponds to the time far before the lock-up expiration date. The following three periods belong to stage II and are denoted by (II, 0), (II, 1), and (II, 2). Stage II represents the dates around the relaxation of these restrictions. The last three periods are in stage III, a time when insiders have sold out all their shares to outsiders, and are denoted by (III, 0), (III, 1), and (III, 2).

The asset pays a liquidating dividend on the final date (III, 2) given by:

$$
D=D_{I}+D_{I I}+D_{I I I}
$$

where the three dividend components $\left(D_{I}, D_{I I}\right.$, and $\left.D_{I I I}\right)$ are independent, identically and normally distributed, $N\left(\bar{D}, \tau_{0}\right)$. There are two groups of outside investors $\mathrm{A}$ and $\mathrm{B}$ 
(as before) and a group of insiders who all share the same information. So there is no information asymmetry between insiders and outsiders in this model. And we assume that all agents in the model, including the insiders, are price takers (i.e. we rule out any sort of strategic behavior).

In Stage I, due to lock-up restrictions, the asset supply is limited to $Q_{f}$, a small fraction of the total shares outstanding, which is denoted by $\bar{Q}$. On date $(I, 1)$, agents receive two signals about $D_{I}$,

$$
s_{I}^{A}=D_{I}+\epsilon_{I}^{A}, \quad s_{I}^{B}=D_{I}+\epsilon_{I}^{B},
$$

where $\epsilon_{I}^{A}$ and $\epsilon_{I}^{B}$ are independent signal noises with identical normal distributions of zero mean and precision of $\tau_{\epsilon}$. Between date (I, 1) and date (II, 0), the first dividend component $D_{I}$ is publicly announced, although it is only paid off at the end of the model.

In stage II, investors start with a float of $Q_{f}$ on date (II, 0). On date (II, 1), two signals on the second dividend component become available

$$
s_{I I}^{A}=D_{I I}+\epsilon_{I I}^{A}, \quad s_{I I}^{B}=D_{I I}+\epsilon_{I I}^{B},
$$

where $\epsilon_{I I}^{A}$ and $\epsilon_{I I}^{B}$ are also independent signal noises with identical normal distributions of zero mean and precision of $\tau_{\epsilon}$. On date (II, 2), many of the insiders' shares, denoted by $Q_{i n}$, become floating-this is known to all in advance. So the total asset supply on this date is $Q_{f}+Q_{i n}<\bar{Q}$. At the lock-up expiration date, insiders rarely are able to trade all their shares for price impact reasons. In practice, it takes some time for all their shares to be floating. The assumption that only $Q_{\text {in }}$ shares are tradeable is meant to capture this. In other words, it typically takes a while after the expiration of lock-ups for all the shares of the firm to be floating. Importantly, the insiders can also trade on this date based on their assessment of the fundamental. The exact value of $D_{I I}$ is announced after date (II, 2) and before the beginning of the next stage.

At the beginning of stage III, date (III, 0), we assume that the insiders are forced to liquidate their positions from Stage II. The market price on this date is determined by the 
demands of the outside investors and the total asset supply of $\bar{Q}$. Insiders' positions are marked and liquidated at this price and they are no longer relevant for price determination during this stage. On date (III, 1), two signals become available on the third dividend component:

$$
s_{I I I}^{A}=D_{I I I}+\epsilon_{I I I}^{A}, \quad s_{I I I}^{B}=D_{I I I}+\epsilon_{I I I}^{B},
$$

where $\epsilon_{I I I}^{A}$ and $\epsilon_{I I I}^{B}$ are independent signal noises with identical normal distributions of zero mean and precision of $\tau_{\epsilon}$. On date (III, 2), the asset is liquidated.

Insiders are assumed to have mean-variance preferences with a total risk tolerance of $\eta_{i n}$. They correctly process all the information pertaining to fundamentals. At date (II, 2), insiders trade to maximize their terminal utility at date (III, 0), when they are forced to liquidate all their positions. Investors in groups $\mathrm{A}$ and $\mathrm{B}$ also have per-period meanvariance preferences, where $\eta$ is the risk tolerance of each group. Unlike the insiders, due to overconfidence, group A over-estimates the precision of the A-signals at each stage as $\phi \tau_{\epsilon}$, while group B over-estimates the precision of the B-signals at each stage as $\phi \tau_{\epsilon}$.

Since investors are overconfident, each group of investors essentially thinks that they are rational and smarter than the other group. Since insiders are typically thought of as having more knowledge about their company than outsiders, it seems natural to assume that each group of investors thinks that the insiders are "smart" or "rational" like them. In other words, each group believes that the insiders are more likely to share their expectations of fundamentals and hence be on the same side of the trade than the insiders are to be like the other group. We assume that they agree to disagree about this proposition. Thus, on date (II, 1) both group-A and group-B investors believe that insiders will trade like themselves on date (II, 2).

Another important assumption that buys tractability but does not change our conclusions is that we do not allow insiders to be active in the market during Stage III. We think this is a reasonable assumption in practice since insiders, because of various insider trading rules, are not likely to be speculators in the market on par with those of outside investors in 
steady state for a company. And we think of Stage III was being a time when insiders have largely cashed out of the company for liquidity reasons. We solve the model by backward induction.

\section{Figure 2: Time Line of Events}

Around-lock-up expiration $\left\{\begin{array}{l}(\mathrm{I}, 0): Q_{f} \text { shares floating } \\ (\mathrm{I}, 1): \text { receive signals } s_{I}^{A} \text { and } s_{I}^{B} \text { on } D_{I} \\ (\mathrm{II}, 0): Q_{f} \text { shares are initially floating } \\ (\mathrm{II}, 1) \text { : receive signals } s_{I I}^{A} \text { and } s_{I I}^{B} \text { on } D_{I I} \\ (\mathrm{II}, 2): \text { insiders allowed to trade, } Q_{f}+Q_{i n} \text { shares floating } \\ (\mathrm{III}, 0): \text { all of the shares of the firm, } \bar{Q}, \text { are floating } \\ (\mathrm{III}, 1) \text { : receive signals } s_{I I I}^{A} \text { and } s_{I I I}^{B} \text { on } D_{I I I} \\ (\mathrm{III}, 2) \text { : asset liquidated, pay out } D_{I}+D_{I I}+D_{I I I}\end{array}\right.$

\subsection{Solution}

\subsubsection{Stage III: Far-after-the-lock-up expiration date}

As we described above, at date (III, 0), insiders are forced to liquidate their positions from Stage II. The market price on this date is determined by the demands of the outside investors and the total asset supply of $\bar{Q}$. Insiders' positions are liquidated at this price and they are no longer relevant for price determination during this stage. Moreover, outsiders' decisions from this point forward depend only on $D_{I I I}$ as $D_{I I}$ has already been revealed. As such, we do not have to deal with what the outside investors learned about $D_{I I}$ and that insiders did not take the same positions as them at date (II, 2).

We denote the beliefs of the two groups of outside investors at date (III, 1) regarding $D_{I I I}$ by $\hat{D}_{I I I}^{A}$ and $\hat{D}_{I I I}^{B}$, respectively. Applying the results from Lemma 1, these beliefs are 
given by $N\left(\hat{D}_{I I I}^{A}, \tau\right)$ and $N\left(\hat{D}_{I I I}^{B}, \tau\right)$, where the precision is given by equation (3) and the means by

$$
\begin{aligned}
& \hat{D}_{I I I}^{A}=\bar{D}+\frac{\phi \tau_{\epsilon}}{\tau}\left(s_{I I I}^{A}-\bar{D}\right)+\frac{\tau_{\epsilon}}{\tau}\left(s_{I I I}^{B}-\bar{D}\right), \\
& \hat{D}_{I I I}^{B}=\bar{D}+\frac{\tau_{\epsilon}}{\tau}\left(s_{I I I}^{A}-\bar{D}\right)+\frac{\phi \tau_{\epsilon}}{\tau}\left(s_{I I I}^{B}-\bar{D}\right) .
\end{aligned}
$$

The solution for equilibrium prices is nearly identical to that obtained from our simple model of the previous section. Applying Lemma 2 and Theorem 1, we have the following equilibrium prices:

$$
\begin{aligned}
& p_{I I I, 2}=D_{I}+D_{I I}+D_{I I I} \\
& p_{I I I, 1}=D_{I}+D_{I I}+ \begin{cases}\max \left(\hat{D}_{I I I}^{A}, \hat{D}_{I I I}^{B}\right)-\frac{\bar{Q}}{\eta \tau} & \text { if }\left|\hat{D}_{I I I}^{A}-\hat{D}_{I I I}^{B}\right| \geq \frac{\bar{Q}}{\eta \tau} \\
\frac{\hat{D}_{I I}^{A}+\hat{D}_{I I I}^{B}}{2}-\frac{\bar{Q}}{2 \eta \tau} & \text { if }\left|\hat{D}_{I I I}^{A}-\hat{D}_{I I I}^{B}\right|<\frac{\bar{Q}}{\eta \tau}\end{cases} \\
& p_{I I I, 0}=D_{I}+D_{I I}+\bar{D}-\frac{\Sigma_{I I I}}{2 \eta} \bar{Q}-\frac{\bar{Q}}{2 \eta \tau}+B(\bar{Q}),
\end{aligned}
$$

where

$$
\Sigma_{I I I}=\operatorname{Var}_{I I I, 0}^{A}\left[p_{I I I, 1}-p_{I I I, 0}\right]=\operatorname{Var}_{I I I, 0}^{B}\left[p_{I I I, 1}-p_{I I I, 0}\right]
$$

Note that $D_{I}$ and $D_{I I}$ have been revealed and are known at the beginning of stage III. The asset is liquidated at date (II, 2), so price just equals fundamentals at this date. At date (III, 1), price depends on the divergence of opinion among $A$ and $B$ investors and whether it is large enough (greater than $\frac{\bar{Q}}{\eta \tau}$ ) for short-sales constraints to bind and therefore for one group's valuation to dominate the market.

For convenience, let

$$
v_{I I I}=\bar{D}-\frac{\Sigma_{I I I}}{2 \eta} \bar{Q}-\frac{\bar{Q}}{2 \eta \tau}+B(\bar{Q}) .
$$

$v_{I I I}$ will be discounted into prices at the earlier stages.

\subsubsection{Stage II: Around-the-lock-up expiration date}

During this stage, the trading is driven entirely by the investors' and the insiders' expectations of $D_{I I}$ because $D_{I I}$ is independent of $D_{I I I}$. In other words, information about $D_{I I}$ 
tells agents nothing about $D_{I I I}$. As a result, the demand functions of agents in this stage mirror the simple mean-variance optimization rules of the previous section.

We begin by specifying the beliefs of the investors after observing the signals at date (II, 1). The rational belief of the insider is

$$
\hat{D}_{I I}^{i n}=\bar{D}+\frac{\tau_{\epsilon}}{\tau_{0}+2 \tau_{\epsilon}}\left(s_{I I}^{A}-\bar{D}\right)+\frac{\tau_{\epsilon}}{\tau_{0}+2 \tau_{\epsilon}}\left(s_{I I}^{B}-\bar{D}\right)
$$

Due to overconfidence, the beliefs of the two groups of investors at date (II, 1) regarding $D_{I I}$ are given by $N\left(\hat{D}_{I I}^{A}, \tau\right)$ and $N\left(\hat{D}_{I I}^{B}, \tau\right)$, where the precision of their beliefs is given by equation (3) and the means of their beliefs by

$$
\begin{aligned}
& \hat{D}_{I I}^{A}=\bar{D}+\frac{\phi \tau_{\epsilon}}{\tau}\left(s_{I I}^{A}-\bar{D}\right)+\frac{\tau_{\epsilon}}{\tau}\left(s_{I I}^{B}-\bar{D}\right), \\
& \hat{D}_{I I}^{B}=\bar{D}+\frac{\tau_{\epsilon}}{\tau}\left(s_{I I}^{A}-\bar{D}\right)+\frac{\phi \tau_{\epsilon}}{\tau}\left(s_{I I}^{B}-\bar{D}\right) .
\end{aligned}
$$

We next specify the investors' beliefs at date (II, 1) about what the insiders will do at date (II, 2). Recall that each group of investors thinks that the insiders are smart like them and will share their beliefs at date (II, 2). As a result, the investors will have different beliefs at date (II, 1) about the prevailing price at date (II, 2), denoted by $p_{I I, 2}$.

\section{A. Calculating A-investors' belief about $p_{I I, 2}$}

In calculating A's belief about $p_{I I, 2}$, note that group-A investors' belief on date (II, 1 ) of the demand functions by each group on date (II, 2) is given by:

$$
\begin{aligned}
& x_{I I, 2}^{i n}=\eta_{i n} \tau \max \left(D_{I}+\hat{D}_{I I}^{A}+v_{I I I}-p_{I I, 2}, 0\right) \\
& x_{I I, 2}^{A}=\eta \tau \max \left(D_{I}+\hat{D}_{I I}^{A}+v_{I I I}-p_{I I, 2}, 0\right) \\
& x_{I I, 2}^{B}=\eta \tau \max \left(D_{I}+\hat{D}_{I I}^{B}+v_{I I I}-p_{I I, 2}, 0\right) .
\end{aligned}
$$

Notice that from A's perspective, the insiders' demand function is determined by $\hat{D}_{I I}^{A}$. This is the sense in which $\mathrm{A}$ thinks that the insiders are like them. The market clearing condition is given by

$$
x_{I I, 2}^{i n}+x_{I I, 2}^{A}+x_{I I, 2}^{B}=Q_{f}+Q_{i n} .
$$


Three possible cases arise depending on the difference in the group A and B's fundamental beliefs.

Case 1: $\hat{D}_{I I}^{A}-\hat{D}_{I I}^{B}>\frac{1}{\tau\left(\eta+\eta_{i n}\right)}\left(Q_{f}+Q_{i n}\right)$. A-investors value the asset much more than Binvestors, and they think insiders share their belief as well. Therefore, A-investors expect that they and the insiders will hold all the shares at (II, 2):

$$
x_{I I, 2}^{A}+x_{I I, 2}^{i n}=Q_{f}+Q_{i n}, \quad x_{I I, 2}^{B}=0 .
$$

As a result, the asset price is determined by A-investors' belief $D_{I I}^{A}$ and a risk premium:

$$
p_{I I, 2}^{A}=D_{I}+v_{I I I}+\hat{D}_{I I}^{A}-\frac{1}{\tau\left(\eta+\eta_{i n}\right)}\left(Q_{f}+Q_{i n}\right) .
$$

We put a superscript $A$ on price $p_{I I, 2}^{A}$ to emphasize that this price is in the mind of groupA investors at (II, 1), although the realized price might be different since insiders do not share the same belief as group-A investors. It is important to note that the risk premium is determined by the total risk bearing capacity of A-investors and insiders, since A-investors expect insiders to share the risk with them.

Case 2: $\left|\hat{D}_{I I, 2}^{A}-\hat{D}_{I I, 2}^{B}\right| \leq \frac{1}{\tau\left(\eta+\eta_{i n}\right)}\left(Q_{f}+Q_{i n}\right)$. Both A-investors and B-investors will end up holding some of the assets at (II, 2), and the market price is jointly determined by their beliefs. Therefore the market equilibrium at (II, 2) will be

$$
\begin{aligned}
x_{I I, 2}^{A}+x_{I I, 2}^{i n} & =\frac{\tau \eta\left(\eta+\eta_{i n}\right)}{2 \eta+\eta_{i n}}\left(\hat{D}_{I I}^{A}-\hat{D}_{I I}^{B}\right)+\frac{\eta+\eta_{i n}}{2 \eta+\eta_{i n}}\left(Q_{f}+Q_{i n}\right), \\
x_{I I, 2}^{B} & =\frac{\tau \eta\left(\eta+\eta_{i n}\right)}{2 \eta+\eta_{i n}}\left(\hat{D}_{I I}^{B}-\hat{D}_{I I}^{A}\right)+\frac{\eta}{2 \eta+\eta_{i n}}\left(Q_{f}+Q_{i n}\right) .
\end{aligned}
$$

Since both groups will participate in the market, the price is determined by a weighted average of the two groups' beliefs, with the weights determined by the risk-bearing capacities, and a risk premium term counting the total risk-bearing capacity in the market:

$$
p_{I I, 2}^{A}=D_{I}+v_{I I I}+\frac{\eta+\eta_{i n}}{2 \eta+\eta_{i n}} \hat{D}_{I I}^{A}+\frac{\eta}{2 \eta+\eta_{i n}} \hat{D}_{I I}^{B}-\frac{1}{\tau\left(2 \eta+\eta_{i n}\right)}\left(Q_{f}+Q_{i n}\right)
$$


Note a larger weight on A-investors' belief, again since they count insiders in their group and these outcomes at (II, 2) are what is expected by the A-investors at (II, 1).

Case 3: $\hat{D}_{I I}^{A}-\hat{D}_{I I}^{B}<-\frac{1}{\tau\left(\eta+\eta_{i n}\right)}\left(Q_{f}+Q_{i n}\right)$. In this case, A-investors' belief is much lower than that of B-investors. Thus, they will stay out of market at (II, 2). In addition, they believe that insiders will also dump all their shares due to their pessimistic belief. As a result, in A-investors' mind, all the shares will be held by B-investors:

$$
x_{I I, 2}^{A}+x_{I I, 2}^{i n}=0, \quad x_{I I, 2}^{B}=Q_{f}+Q_{i n}
$$

As a result, the asset price is determined by B-investors' belief:

$$
p_{I I, 2}^{A}=D_{I}+v_{I I I}+\hat{D}_{I I}^{B}-\frac{1}{\tau \eta}\left(Q_{f}+Q_{i n}\right)
$$

Note that the risk premium term only counts B-investors' risk-bearing capacity since Ainvestors expect insiders to stay out of the market as they are.

\section{B. Calculating B-investors' belief about $p_{I I, 2}$}

Following a similar procedure as for group-A investors, we can derive the price at date (II, 2) expected B-investors:

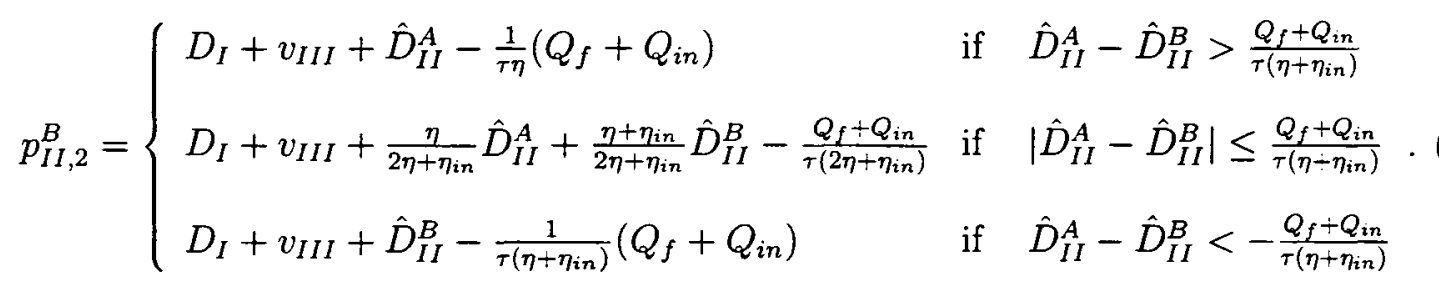

Notice that $p_{I I, 2}^{B}$ is similar in form to $p_{I I, 2}^{A}$ except that B-investors think that the insiders share their expectations, $\hat{D}_{I I}^{B}$, and be on the same side of the trade as them.

\section{Solving for $p_{I I, 1}$ and $p_{I I, 0}$}

The price at (II, 1) is determined by $p_{I I, 2}^{A}$ and $p_{I I, 2}^{B}$. If $Q_{i n}$ is perfectly known at (II, 1 ), there is no uncertainty between dates (II, 1) and (II, 2). Thus, group-A investors are willing to trade an infinite amount if the price $p_{I I, 1}$ is less than $p_{I I, 2}^{A}$, while group- $\mathrm{B}$ investors are 
willing to trade an infinite amount if the price $p_{I I, 1}$ is less than $p_{I I, 2}^{B}$. As a result, at (II, 1), the asset price is determined by the higher one of $p_{I I, 2}^{A}$ and $p_{I I, 2}^{B}$ :

$$
p_{I I, 1}=\max \left(p_{I I, 2}^{A}, p_{I I, 2}^{B}\right) .
$$

Let $l_{I I}=\hat{D}_{I I}^{A}-\hat{D}_{I I}^{B}$. We can express the equilibrium price at (II, 1) as the following:

$$
\begin{aligned}
p_{I I, 1}=D_{I}+ & v_{I I I}+\hat{D}_{I I}^{B}-\frac{Q_{f}+Q_{i n}}{\tau\left(2 \eta+\eta_{i n}\right)} \\
& +\left\{\begin{array}{ll}
-\frac{1}{\tau}\left[\frac{1}{\eta+\eta_{i n}}-\frac{1}{2 \eta+\eta_{i n}}\right]\left(Q_{f}+Q_{i n}\right) & \text { if } l_{I I}<-\frac{Q_{f}+Q_{i n}}{\tau\left(\eta+\eta_{i n}\right)} \\
\frac{\eta}{2 \eta+\eta_{i n}} l_{I I} & \text { if }-\frac{Q_{f}+Q_{i n}}{\tau\left(\eta+\eta_{i n}\right)}<l_{I I}<0 \\
\frac{\eta+\eta_{i n}}{2 \eta+\eta_{i n}} l_{I I} & \text { if } 0<l_{I I}<\frac{Q_{f}+Q_{i n}}{\tau\left(\eta+\eta_{i n}\right)} \\
l_{I I}-\frac{1}{\tau}\left[\frac{1}{\eta+\eta_{i n}}-\frac{1}{2 \eta+\eta_{i n}}\right]\left(Q_{f}+Q_{i n}\right) & \text { if } l_{I I}>\frac{Q_{f}+Q_{i n}}{\tau\left(\eta+\eta_{i n}\right)}
\end{array} .\right.
\end{aligned}
$$

There are two uncertain terms in this price function, group-B investors' belief $\left(\hat{D}_{I I}^{B}\right)$ and the four-piece function of the difference in beliefs $l_{I I}$. The four-piece function is analogous to the triplet function of the previous section and represents the resale option for group- $B$ investors. (Symmetrically, we can express this price function in terms of group-A investors' belief and a four-piece function that is the resale option for group-A investors.)

Given the expectations of group-A and group-B agents at (II, 0 ) of $p_{I I, 1}$, we can derive the market clearing price:

$$
p_{I I, 0}=\frac{1}{2}\left[\mathrm{E}_{I I, 0}^{A}\left[p_{I I, 1}\right]+\mathrm{E}_{I I, 0}^{B}\left[p_{I I, 1}\right]\right]-\frac{\Sigma_{I I}}{2 \eta} Q_{f}
$$

where

$$
\Sigma_{I I}=\operatorname{Var}_{I I, 0}^{A}\left[p_{I I, 1}-p_{I I, 0}\right]=\operatorname{Var}_{I I, 0}^{B}\left[p_{I I, 1}-p_{I I, 0}\right]
$$

The following theorem gives the conditional expectations and equilibrium price at date $(\mathrm{II}, 0)$.

Theorem 2 At date $(I I, 0)$, the conditional expectation of $A$-investors and $B$-investors regarding $p_{I I, 1}$ are identical:

$$
\mathrm{E}_{I I, 0}^{A}\left[p_{I I, 1}\right]=\mathrm{E}_{I I, 0}^{B}\left[p_{I I, 1}\right]=D_{I}+v_{I I I}+\hat{D}_{I I}^{B}-\frac{Q_{f}+Q_{i n}}{\tau\left(2 \eta+\eta_{i n}\right)}+B_{I I}
$$


where

$$
\begin{aligned}
& B_{I I}=\mathrm{E}\left[\left(l_{I I}-\frac{\left(Q_{f}+Q_{i n}\right)}{\tau\left(\eta+\eta_{i n}\right)}\right) I_{\left\{l_{I I}>\frac{Q_{f}+Q_{i n}}{\tau\left(\eta+\eta_{i n}\right)}\right\}}\right]+\mathrm{E}\left[\frac{\eta_{i n} l_{I I}}{2 \eta+\eta_{i n}} I_{\left\{0<l_{I I}<\frac{Q_{f}+Q_{i n}}{\tau\left(\eta+\eta_{i n}\right)}\right\}}\right] \\
& +\frac{\eta_{i n}\left(Q_{f}+Q_{i n}\right)}{\tau\left(\eta+\eta_{i n}\right)\left(2 \eta+\eta_{i n}\right)} \mathrm{E}\left[I_{\left\{l_{I I}>\frac{Q_{f}+Q_{i n}}{\tau\left(\eta+\eta_{i n}\right)}\right\}}\right] \text {. }
\end{aligned}
$$

Then the price at date $(I I, 0)$ is

$$
p_{I I, 0}=D_{I}+v_{I I I}+\bar{D}-\frac{\Sigma_{I I}}{2 \eta} Q_{f}-\frac{Q_{f}+Q_{i n}}{\tau\left(2 \eta+\eta_{i n}\right)}+B_{I I}
$$

Notice that when $\eta_{i n}=0$ (i.e. insiders are infinitely risk averse), then the bubble $B_{I I}$ reduces to

$$
\mathrm{E}\left[\left(l_{I I}-\frac{\left(Q_{f}+Q_{i n}\right)}{\tau \eta}\right) I_{\left\{l_{I I}>\frac{Q_{f}+Q_{i n}}{\tau \eta}\right\}}\right],
$$

which is similar to the bubble derived in the previous section except that asset supply is now $Q_{f}+Q_{i n}$. Note that this option value is determined by the total shares $Q_{f}+Q_{\text {in }}$ and not $Q_{f}$. Although the lock-up period only expires after the the beliefs of groups A and B investors are realized at (II, 1), all investors anticipate more shares to come into the market at (II, 2), and therefore adjust their option value accordingly.

Since investors are overconfident, each group of investors naturally believes that the insiders are "smart" like them. Indeed, they agree to disagree about this proposition. As a result, each group of investors expects the other group to be more aggressive in taking positions in the future since the other group expects that the insiders will eventually come in and share the risk of their positions with them. As a result, each group believes that they can profit more from their resale option when the other group has a higher belief. As we show below, it turns out that the bubble is, all else equal, larger as a result of the outsiders believing that the insiders are smart like them. So just as long as insiders decide how to sell their positions based on their belief about fundamentals, this effect will be present. 
Let

$$
v_{I I}=\bar{D}-\frac{\Sigma_{I I}}{2 \eta} Q_{f}-\frac{Q_{f}+Q_{i n}}{\tau\left(2 \eta+\eta_{i n}\right)}+B_{I I}
$$

represent the value associated with trade in Stage II. It will be discounted into the prices of Stage I.

\subsubsection{Stage I: Before-the-lock-up expiration date}

We denote the beliefs of the two groups of outside investors at date $(I, 1)$ regarding $D_{I}$ by $\hat{D}_{I}^{A}$ and $\hat{D}_{I}^{B}$, respectively. Applying the results from Lemma 1 , these beliefs are given by $N\left(\hat{D}_{I}^{A}, \tau\right)$ and $N\left(\hat{D}_{I}^{B}, \tau\right)$, where the precision is given by equation (3) and the means by

$$
\begin{aligned}
& \hat{D}_{I}^{A}=\bar{D}+\frac{\phi \tau_{\epsilon}}{\tau}\left(s_{I}^{A}-\bar{D}\right)+\frac{\tau_{\epsilon}}{\tau}\left(s_{I}^{B}-\bar{D}\right), \\
& \hat{D}_{I}^{B}=\bar{D}+\frac{\tau_{\epsilon}}{\tau}\left(s_{I}^{A}-\bar{D}\right)+\frac{\phi \tau_{\epsilon}}{\tau}\left(s_{I}^{B}-\bar{D}\right) .
\end{aligned}
$$

Since stage I is very much similar to the basic model, we can directly calculate the prices as

$$
\begin{aligned}
& p_{I, 1}=v_{I I}+v_{I I I}+ \begin{cases}\max \left(\hat{D}_{I}^{A}, \hat{D}_{I}^{B}\right)-\frac{Q_{f}}{\eta \tau}, & \text { if }\left|\hat{D}_{I}^{A}-\hat{D}_{I}^{B}\right| \geq \frac{Q_{f}}{\eta \tau} \\
\frac{\hat{D}_{I}^{A}+\hat{D}_{I}^{B}}{2}-\frac{Q_{f}}{2 \eta \tau} & \text { if }\left|\hat{D}_{I}^{A}-\hat{D}_{I}^{B}\right|<\frac{Q_{f}}{\eta \tau}\end{cases} \\
& p_{I, 0}=v_{I I}+v_{I I I}+\bar{D}-\frac{\Sigma_{I}}{2 \eta} Q_{f}-\frac{Q_{f}}{2 \eta \tau}+B\left(Q_{f}\right),
\end{aligned}
$$

where

$$
\Sigma_{I}=\operatorname{Var}_{I, 0}^{A}\left[p_{I, 1}-p_{I, 0}\right]=\operatorname{Var}_{I, 0}^{B}\left[p_{I, 1}-p_{I, 0}\right]
$$

\section{Discussions}

In this section, we discuss how our theory yields a number of predictions, some of which are consistent with stylized facts regarding the behavior of the internet stocks during the late nineties. 


\subsection{Float and the cross-section of expected returns}

One of the main predictions of our model is that a stock with a limited float to risk-bearing capacity will have a larger price bubble and hence a lower expected return going forward. In reality, stocks with a low ratio of float to risk bearing capacity may be easier to arbitrage and hence may exhibit less mis-pricing. For instance, one proxy for the ratio of float to risk-bearing capacity might be the market capitalization or the analyst coverage of a stock. And one often thinks that large stocks are indeed easier to arbitrage than small stocks.

So, more interesting from our perspective is that even controlling for firm size (i.e. for float and risk-bearing capacity), our model predicts that the float of a stock will have an independent effect on expected return. In other words, in our model, float is not simply a proxy for the size of a stock. The reason float matters is that, as we showed in Theorem 2, the very event of potential insider selling at the end of the lock-up period leads to a larger bubble than would have otherwise occurred. As a result, we have the following proposition:

Proposition 4 Even controlling for asset supply and risk bearing capacity (i.e. firm size), a stock with a limited float and hence a greater potential for insider selling will have a larger bubble and hence a lower expected return.

\subsection{Bubble before and after lock-up expiration date}

One of the most striking of stylized facts of the internet period is that the bubble bursted in the Spring of 2000 when the float of the internet sector dramatically increased. There are a couple of explanations for this stylized fact. The first, as we alluded to above, is the relaxation of short-sales constraints story. Another one is that investors may have learned after the lock-ups expired that internet valuations were not justified based on insider sales. ${ }^{11}$

Nonetheless, there is clearly room for alternative explanations given the empirical evidence. For instance, it is difficult to tie the decline in internet valuations in the Spring of 2000 merely to a relaxation of short-sales constraints (see Ofek and Richardson (2003)).

\footnotetext{
${ }^{11} \mathrm{~A}$ particular version of this learning story related to our model is that investors may have become less overconfident after observing the trades of insiders.
} 
And it is not likely that trading volume and return volatility also dried up after the bubble bursted because of variations in short-selling costs.

As such, our model provides a distinct alternative to existing theories. The key results are summarized in the following proposition.

Proposition 5 The bubble component in asset prices is smaller after the lock-up expiration date than before, i.e. $B(\bar{Q})$, the bubble component in Stage III, is less than $B\left(Q_{f}\right)$ and $B_{I I}$, the bubble components in Stages I and II, respectively. Moreover, turnover and return volatility in Stage III is less than turnover and return volatility in Stages I and II.

To the extent that the risk absorption capacity stayed the same but the asset supply increased, our model predicts that it requires a bigger divergence of opinion to sustain the bubble, leading to a smaller bubble and less trading volume and volatility. Even more interestingly, after the expiration of lock-up restrictions, the speculation regarding the degree of insider selling also diminished, again leading to a smalier bubble.

\subsection{Price change across the lock-up expiration date}

Another outstanding stylized fact regarding internet stocks during the late nineties involve price dynamics across the lock-up expiration date. Empirical evidence suggests that stock prices tend to decline on the day of the event (see Brav and Gompers (2003), Field and Hanka (2001) and Ofek and Richardson (2000)). This finding is puzzling since the date of this event is known to all in advance.

However, our model is able to rationalize it with the following proposition.

Proposition 6 When the maximum of the two signals $s_{I I}^{A}$ and $s_{I I}^{B}$ is larger than the prior $\bar{D}$, the stock price falls on the lock-up expiration date, date (II,2) (i.e. $p_{I I, 2}<p_{I I, 1}$ ).

At (II, 1), right before the lock-up expiration at (II, 2), agents from the more optimistic group anticipate that insiders will share their belief after the lock-up expiration. Since insiders are rational (i.e. properly weighing the two public signals), they have a different 
belief than the overconfident investors. We show that their belief will be lower than that of the optimistic investors. As a result, there will be more selling on the part of insiders on the lock-up expiration date than is anticipated by the optimistic group holding the asset before the lock-up expiration. Hence, the stock price falls on this date.

To demonstrate this, we denote $o \in\{A, B\}$ as the group with the optimistic belief at (II, 1), and $\bar{o}$ as the other group, (i.e. $\hat{D}_{I I}^{o} \geq \hat{D}_{I I}^{\bar{o}}$ ). Note that the signal overweighted by the optimistic group (denoted by $s_{I I}^{o}$ ) is higher than the signal overweighted by the pessimistic group (denoted by $s_{I I}^{\bar{o}}$ ). Based on the beliefs of overconfident investors in equations (31) and (32), and the belief of insiders in equation (30), we can derive the difference between the optimistic investors' belief and insiders' belief as

$$
\hat{D}_{I I}^{o}-\hat{D}_{I I}^{i n}=\tau_{\epsilon}\left(\frac{\phi}{\tau}-\frac{1}{\tau_{0}+2 \tau_{\epsilon}}\right)\left(s_{I I}^{o}-\bar{D}\right)+\tau_{\epsilon}\left(\frac{1}{\tau}-\frac{1}{\tau_{0}+2 \tau_{\epsilon}}\right)\left(s_{I I}^{\bar{o}}-\bar{D}\right) .
$$

We show that

$$
\hat{D}_{I I}^{o}-\hat{D}_{I I}^{i n} \geq \frac{(\phi-1) \tau_{0} \tau_{\epsilon}}{\tau\left(\tau_{0}+2 \tau_{\epsilon}\right)}\left(s_{I I}^{o}-\bar{D}\right)
$$

When $s_{I I}^{o}>\bar{D}$, it follows that the belief of the optimistic group will be higher than the insiders'. However, price is a non-linear function of this difference in beliefs because of short-sales constraints. So it does not immediately follow that price drops on date (II, 2). But it turns out that price indeed drops on this date (i.e. $p_{I I, 2}<p_{I I, 1}$ ) as a result of this difference.

Studies typically find that among IPOs, around sixty-percent of them exhibit negative abnormal returns on the lock-up expiration date (see, e.g., Brav and Gompers (2003)). This figure can be rationalized by our model. Since the signals $s_{I I}^{A}$ and $s_{I I}^{B}$ are symmetrically distributed around $\bar{D}$ (in objective measure), it follows that if we were to draw these signals infinitely many times (assuming independence in the cross-section), over fifty percent of the time, the maximum of the two signals will be greater than $\bar{D}$. Indeed, we can derive the probability of this as

$$
\operatorname{Pr}\left[\max \left(s_{I I}^{A}, s_{I I}^{B}\right)>\bar{D}\right]=\operatorname{Pr}\left[\max \left(D_{I I}-\bar{D}+\epsilon_{I I}^{A}, D_{I I}-\bar{D}+\epsilon_{I I}^{B}\right)>0\right]
$$




$$
\begin{aligned}
& =1-\operatorname{Pr}\left[D_{I I}-\bar{D}+\epsilon_{I I}^{A} \leq 0, D_{I I}-\bar{D}+\epsilon_{I I}^{B} \leq 0\right] \\
& =\frac{3}{4}-\frac{1}{2 \pi} \operatorname{ArcTan}\left(\frac{\rho}{\sqrt{1-\rho^{2}}}\right)
\end{aligned}
$$

where $\rho$, the correlation parameter between $s_{I I}^{A}$ and $s_{I I}^{B}$, is given by

$$
\rho=\frac{\tau_{\epsilon}}{\tau_{0}+\tau_{\epsilon}}
$$

The correlation parameter $\rho$ is naturally between 0 and 1 in our model. As $\rho$ increases from 0 to 1 , the probability decreases from $75 \%$ to $50 \%$. Needless to say that the sixty-percent figure found in empirical studies fits comfortably within these bounds.

\section{Conclusion}

In this paper, we develop a discrete-time, multi-period model to understand the relationship between the float of an asset (the publicly tradeable shares) and the propensity for speculative bubbles to form. Investors trade a stock that initially has a limited float because of insider lock-up restrictions but the tradeable shares of which increase over time as these restrictions expire. They are assumed to have heterogeneous beliefs due to overconfidence and are short-sales constrained. As a result, they pay prices that exceed their own valuation of future dividends because they anticipate finding a buyer willing to pay even more in the future. This resale option imparts a bubble component in asset prices. With limited risk absorption capacity, this resale option depends on float as investors anticipate the change in asset supply over time and speculate over the degree of insider selling.

Our model yields a number of empirical implications that are consistent with stylized accounts of the importance of float for the behavior of internet stock prices during the late nineties. These implications include: 1) a stock price bubble dramatically decreases with float; 2) share turnover and return volatility also decrease with float; and 3) the stock price tends to decline on the lock-up expiration date even though it is known to all in advance. 


\section{Appendix}

\subsection{Proof of Lemma 1}

See DeGroot (1970).

\subsection{Proof of Lemma 2}

Proof follows from substituting in the equilibrium price into demands given in equation (6) and checking that the market clears.

\subsection{Proof of Theorem 1}

To derive the expectation of B-investors about $p_{1}$, we directly use equation (13):

$$
\begin{aligned}
& \mathrm{E}_{0}^{B}\left[p_{1}\right]=\mathrm{E}_{0}^{B}\left[\hat{f}_{1}^{B}\right]-\frac{Q}{2 \eta \tau}-\mathrm{E}_{0}^{B}\left[\frac{Q}{2 \eta \tau} I_{\left\{l_{1}<-\frac{Q}{\eta \tau}\right\}}\right]+\mathrm{E}_{0}^{B}\left[\frac{l_{1}}{2} I_{\left\{-\frac{Q}{\eta \tau}<l_{1}<\frac{Q}{\eta \tau}\right\}}\right] \\
&+\mathrm{E}_{0}^{B}\left[\left(l_{1}-\frac{Q}{2 \eta \tau}\right) I_{\left\{l_{1}>\frac{Q}{\eta \tau}\right\}}\right]
\end{aligned}
$$

Since $l_{1}$ has a symmetric distribution around zero, we obtain that

$$
\mathrm{E}_{0}^{B}\left[\frac{Q}{2 \eta \tau} I_{\left\{l_{1}<-\frac{Q}{\eta \tau}\right\}}\right]=\mathrm{E}_{0}^{B}\left[\frac{Q}{2 \eta \tau} I_{\left\{l_{1}>\frac{Q}{\eta \tau}\right\}}\right]
$$

and

$$
\mathrm{E}_{0}^{B}\left[\frac{l_{1}}{2} I_{\left\{-\frac{Q}{\eta \tau}<l_{1}<\frac{Q}{\eta \tau}\right\}}\right]=0 .
$$

Thus, it is direct to verify $\mathrm{E}_{0}^{B}\left[p_{1}\right]$ in equation (16).

\subsection{Proof of Proposition 1}

Define $K=\frac{Q}{\eta_{T}}$. Note that $l_{1}$ has a normal distribution with zero mean and a variance of $\sigma_{l}^{2}$. Thus, we have

$$
\begin{aligned}
B(Q) & =\mathrm{E}\left[\left(l_{1}-K\right) I_{\left\{l_{1}>K\right\}}\right] \\
& =\int_{K}^{\infty} d l \frac{(l-K)}{\sqrt{2 \pi} \sigma_{l}} e^{-\frac{l^{2}}{2 \sigma_{l}^{2}}} \\
& =\sigma_{l}\left[\sqrt{\frac{2}{\pi}} e^{-\frac{K^{2}}{2 \sigma_{l}^{2}}}-\frac{K}{\sigma_{l}} N\left(-K / \sigma_{l}\right)\right] .
\end{aligned}
$$


Direct differentiation with respect to $Q$ yields

$$
B^{\prime}(Q)=-\frac{1}{\eta \tau} N\left(-\frac{Q}{\eta \tau \sigma_{l}}\right)-\frac{1}{\sqrt{2 \pi}} \frac{Q}{\eta^{2} \tau^{2} \sigma_{l}} e^{-\frac{Q^{2}}{2 \eta^{2} \tau^{2} \sigma_{l}^{2}}}
$$

The size of the bubble also depends on investor overconfidence $\phi$, the determinant of the underlying asset - the difference in beliefs. $\phi$ has two effects on the speculative components.

First, the volatility of $l_{1}$ increases with $\phi$. It is direct to verify that $\sigma_{l}^{2}$ in equation (15) strictly increases with $\phi$ :

$$
\frac{\partial \sigma_{l}^{2}}{\partial \phi}=\frac{\tau_{\epsilon}(\phi-1)\left[\left(2 \phi^{2}+\phi+1\right) \tau_{0}+(\phi+1)(3 \phi+1) \tau_{\epsilon}\right]}{\phi^{2}\left[\tau_{0}+(1+\phi) \tau_{\epsilon}\right]^{3}}>0 .
$$

Second, an increase in $\phi$ raises the belief precision $\tau$, which in turn raises the payoff function for resale options at $t=1$. Therefore, both speculative component increases with $\phi$.

The bubble also depends on the precision of signals $\tau_{\epsilon} \cdot \tau_{\epsilon}$ also has two effects. On the one hand, $\tau$ increases with $\tau_{\epsilon}$. Thus, an increases in $\tau_{\epsilon}$ raises the re-sale option payoff functions. On the other hand, $\tau_{\epsilon}$ affects $\sigma_{l}^{2}$ in a non-monotonic way. It is easy to show that

$$
\frac{\partial \sigma_{l}^{2}}{\partial \sigma_{\epsilon}} \propto\left[\tau_{0}+(1+\phi) \tau_{\epsilon}\right]\left[\tau_{0}-(1+\phi) \tau_{\epsilon}\right]
$$

Thus, $\sigma_{l}^{2}$ increases with $\tau_{\epsilon}$ when $\tau_{\epsilon}<\tau_{0} /(1+\phi)$, and decreases with $\tau_{\epsilon}$ when $\tau_{\epsilon} \geq \tau_{0} /(1+\phi)$. Therefore, an increases in $\tau_{\epsilon}$ will raise both option components when $\tau_{\epsilon}$ is small $\left(\tau_{\epsilon}<\right.$ $\left.\tau_{0} /(1+\phi)\right)$, but its effect becomes ambiguous when $\tau_{\epsilon}$ becomes larger.

\subsection{Proof of Proposition 2}

Direct differentiation yields

$$
B^{\prime \prime}(Q)=\frac{k^{2} e^{-k^{2} / 2}}{\sqrt{2 \pi} \eta^{2} \tau^{2} \sigma_{l}}>0
$$

Thus, $B(Q)$ is convex. It is direct to see that $B^{\prime}(Q)$ is always negative. Its magnitude $\left|B^{\prime}(Q)\right|$ peaks at $Q=0$ with a value of $\frac{1}{2 \eta \tau}$, and it monotonically diminishes as $Q$ becomes large. 
The asset price elasticity with respect to share supply is given by

$$
\frac{Q}{p_{0}} \frac{d p_{0}}{d Q}=-\frac{Q}{p_{0}}\left[\frac{\Sigma+Q d \Sigma / d Q}{2 \eta}+\frac{1}{2 \eta \tau}+\left|B^{\prime}(Q)\right|\right] .
$$

The bubble component $B(Q)$ adds to the price elasticity to asset supply.

\subsection{Proof of Proposition 3}

At $t=0, x_{0}^{A}=x_{0}^{B}=Q / 2$. We define the trading volume at $t=1$ by $\left|x_{1}^{A}-x_{1}^{B}\right| / 2$, and the share turnover rate by

$$
\rho_{0 \rightarrow 1}=\frac{\left|x_{1}^{A}-x_{1}^{B}\right|}{2 Q}
$$

By using our discussion of the equilibrium at $t=0$ above, we can show

$$
\rho_{0 \rightarrow 1}=\left\{\begin{array}{lll}
\frac{1}{2} & \text { if } & \hat{f}_{1}^{A}-\hat{f}_{1}^{B}>\frac{Q}{\eta \tau} \\
\frac{\eta \tau}{2 Q}\left|\hat{f}_{1}^{A}-\hat{f}_{1}^{B}\right| & \text { if } & \left|\hat{f}_{1}^{A}-\hat{f}_{1}^{B}\right| \leq \frac{Q}{\eta \tau} \\
\frac{1}{2} & \text { if } & \hat{f}_{1}^{A}-\hat{f}_{1}^{B}<-\frac{Q}{\eta \tau}
\end{array}\right.
$$

Define $h=\frac{\eta \tau}{Q}\left(\hat{f}_{1}^{A}-\hat{f}_{1}^{B}\right)$. Then,

$$
\rho_{0 \rightarrow 1}= \begin{cases}\frac{1}{2} & \text { if } \quad h>1 \\ \frac{|h|}{2} & \text { if } \quad-1 \leq h \leq 1 \\ \frac{1}{2} & \text { if } \quad h<-1\end{cases}
$$

Using equations (4) and (5), we obtain

$$
h=\frac{\eta(\phi-1)}{Q} \tau_{\epsilon}\left(\epsilon_{f}^{A}-\epsilon_{f}^{B}\right)
$$

Thus, $h$ has a normal distribution with a zero mean and a variance of $\frac{2 \eta^{2}(\phi-1)^{2}}{Q^{2}}$ in the objective probability measure.

It is easy to see that as $Q$ increases, the distribution of $h$ becomes more centered around zero. In the mean time $\rho_{0 \rightarrow 1}$ has a bigger value away from zero, therefore $\mathrm{E}_{0}[\rho(h)]$ decreases with $Q$. Intuitively, when more shares are floating, it takes a bigger difference in beliefs 
to turn all the shares over. Fixing all the other things, the expected share turnover rate decreases with float.

Similarly, as $\phi$ increases, the distribution of $h$ becomes more dispersed. As a result, $\rho_{0 \rightarrow 1}$ rises. Intuitively, when agents are more overconfident, there is more dispersion in beliefs, and therefore more turnover.

On the other hand, the turnover is indifferent to the precision of signals $\tau_{\epsilon}$. This result is a bit surprising. It is due to two effects caused by the precision of signals. On the one

side, $\tau_{\epsilon}$ affects the dispersion of beliefs. On the other side, it also affects the remaining uncertainty in agents' belief. The two effects turn out to exactly offset each other.

To discuss price volatility from $t=0$ to $t=1$, we can re-write

$$
p_{1}=\text { constant }+ \begin{cases}\frac{f_{1}^{A}+\hat{f}_{1}^{B}}{2}-\frac{Q}{2 \eta \tau}+\frac{\hat{f}_{1}^{A}-\hat{f}_{1}^{B}}{2}-\frac{Q}{2 \eta \tau} & \text { if } \quad \hat{f}_{1}^{A}-\hat{f}_{1}^{B}>\frac{Q}{\eta \tau} \\ \frac{\hat{f}_{1}^{A}+\hat{f}_{1}^{B}}{2}-\frac{Q}{2 \eta \tau} & \text { if } \quad\left|\hat{f}_{1}^{A}-\hat{f}_{1}^{B}\right| \leq \frac{Q}{\eta \tau} \\ \frac{\hat{f}_{1}^{A}+\hat{f}_{1}^{B}}{2}-\frac{Q}{2 \eta \tau}-\frac{\hat{f}_{1}^{A}-\hat{f}_{1}^{B}}{2}-\frac{Q}{2 \eta \tau} & \text { if } \quad \hat{f}_{1}^{A}-\hat{f}_{1}^{B}<-\frac{Q}{\eta \tau}\end{cases}
$$

It is important to note that $\frac{\hat{f}_{\perp}^{A}+\hat{f}_{1}^{B}}{2}$ and $\frac{\hat{f}_{\perp}^{A}-\hat{f}_{1}^{B}}{2}$ are independent in an objective measure. Define $l_{1}=\hat{f}_{1}^{A}-\hat{f}_{1}^{B}$, we obtain

$$
p_{1}=\text { constant }+\frac{\hat{f}_{1}^{A}+\hat{f}_{1}^{B}}{2}-\frac{Q}{2 \eta \tau}+G\left(l_{1}\right)
$$

where

$$
G\left(l_{1}\right)= \begin{cases}\frac{1}{2}\left(l_{1}-\frac{Q}{\eta \tau}\right) & \text { if } \quad l_{1}>\frac{Q}{\eta \tau} \\ 0 & \text { if } \quad-\frac{Q}{\eta \tau} \leq l_{1} \leq \frac{Q}{\eta \tau} \\ -\frac{1}{2}\left(l_{1}+\frac{Q}{\eta \tau}\right) & \text { if } l_{1}<-\frac{Q}{\eta \tau}\end{cases}
$$

The price volatility from $t=0$ to $t=1$ has two components:

$$
\operatorname{Var}\left[p_{1}-p_{0}\right]=\operatorname{Var}\left[\left(\hat{f}_{1}^{A}+\hat{f}_{1}^{B}\right) / 2\right]+\operatorname{Var}\left[G\left(l_{1}\right)\right]
$$

One from the volatility of the average belief, and the other from the volatility of the triplet function of the difference in beliefs. The first component is independent of the float. The 
second component decreases with $Q$. To demonstrate this, we only need to show that $\operatorname{Var}\left[G\left(l_{1}\right)\right]$ decreases with $A=\frac{Q}{\eta \tau}$. Direct integration provides that

$$
\begin{aligned}
\operatorname{Var}\left[G\left(l_{1}\right)\right]= & \frac{1}{2}\left[\left(A^{2}+\sigma_{l}^{2}\right) N\left(-A / \sigma_{l}\right)-\frac{A \sigma_{l}}{\sqrt{2 \pi}} e^{-A^{2} / 2 \sigma_{l}^{2}}\right] \\
& -\left[\frac{\sigma_{l}}{\sqrt{2 \pi}} e^{-A^{2} / 2 \sigma_{l}^{2}}-A N\left(-A / \sigma_{l}\right)\right]^{2}
\end{aligned}
$$

which decreases with $A$.

\subsection{Proof of Theorem 2}

Using equation (46), the B-investors' expectation can be expressed as

$$
\begin{aligned}
\mathrm{E}_{I I, 0}^{B}\left[p_{I I, 1}\right]= & \mathrm{E}_{I I, 0}^{B}\left[\hat{D}_{I I}^{B}\right]-\frac{Q_{f}+Q_{i n}}{\tau\left(2 \eta+\eta_{i n}\right)} \\
& -\mathrm{E}_{I I, 0}^{B}\left[\frac{\left(Q_{f}+Q_{i n}\right)}{\tau}\left(\frac{1}{\eta+\eta_{i n}}-\frac{1}{2 \eta+\eta_{i n}}\right) I_{\left.\left\{l_{I I}<-\frac{Q_{f}+Q_{i n}}{\tau\left(\eta+\eta_{i n}\right)}\right\}\right]}\right] \\
& +\mathrm{E}_{I I, 0}^{B}\left[\frac{\eta}{2 \eta+\eta_{i n}} l_{I I} I_{\left\{-\frac{Q_{f}+Q_{i n}}{\tau\left(\eta+\eta_{i n}\right)}<l_{I I}<0\right\}}\right]+\mathrm{E}_{I I, 0}^{B}\left[\frac{\eta+\eta_{i n}}{2 \eta+\eta_{i n}} l_{I I} I_{\left.\left\{0<l_{I I}<\frac{Q_{f}+Q_{i n}}{\tau\left(\eta+\eta_{i n}\right)}\right\}\right]}\right] \\
& +\mathrm{E}_{I I, 0}^{B}\left[\left(l_{I I}-\frac{\left(Q_{f}+Q_{i n}\right)}{\tau}\left(\frac{1}{\eta+\eta_{i n}}-\frac{1}{2 \eta+\eta_{i n}}\right)\right) I_{\left.\left\{l_{I I}>\frac{Q_{f}+Q_{i n}}{\tau\left(\eta+\eta_{i n}\right)}\right\}\right]}\right. \text { (A19) }
\end{aligned}
$$

Since $l_{I I}$ has a symmetric distribution around zero,

$$
\begin{aligned}
\mathrm{E}_{I I, 0}^{B} & {\left[\frac{\left(Q_{f}+Q_{i n}\right)}{\tau}\left(\frac{1}{\eta+\eta_{i n}}-\frac{1}{2 \eta+\eta_{i n}}\right) I_{\left.\left\{l_{H I}<-\frac{Q_{f}+Q_{i n}}{\tau\left(\eta+\eta_{i n}\right)}\right\}\right]}\right] } \\
= & \mathrm{E}_{I I, 0}^{B}\left[\frac{\left(Q_{f}+Q_{i n}\right)}{\tau}\left(\frac{1}{\eta+\eta_{i n}}-\frac{1}{2 \eta+\eta_{i n}}\right) I_{\left\{l_{I I}>\frac{Q_{f}+Q_{i n}}{\tau\left(\eta+\eta_{i n}\right)}\right\}}\right],
\end{aligned}
$$

and

$$
\mathrm{E}_{I I, 0}^{B}\left[\frac{\eta}{2 \eta+\eta_{i n}} l_{I I} I_{\left\{-\frac{Q_{f}+Q_{i n}}{\tau\left(\eta+\eta_{i n}\right)}<l_{I I}<0\right\}}\right]=-\mathrm{E}_{I I, 0}^{B}\left[\frac{\eta}{2 \eta+\eta_{i n}} l_{I I} I_{\left\{0<l_{I I}<\frac{Q_{f}+Q_{i n}}{\tau\left(\eta+\eta_{i n}\right)}\right\}}\right] .
$$

Then, it is direct to verify $\mathrm{E}_{I I, 0}^{B}\left[p_{I I, 1}\right]$ in equation (49).

\subsection{Proof of Proposition 4}

We compare the bubble component for two otherwise identical firms, $L$ and $U$. Firm $L$ ( $L$ as "locked up") has $Q_{f}$ shares floating and $Q_{i n}$ shares by insiders that are to be unlocked as 
specified in the model. The magnitude of the bubble component $B^{L}$ is specified in equation (50).

For Firm $U$ ( $U$ as unlocked), insiders' shares are already unlocked with a total of $Q_{f}+Q_{\text {in }}$ shares floating for two groups of overconfident investors as in the basic model of Section 3 without insiders. To control for the risk bearing capacity in the market, we assume that the risk-bearing capacity of the two groups of insiders is $\eta+\eta_{i n} / 2$ each. Thus there is the same amount risk-bearing capacity in the market for both firms $L$ and $U$. They differ only in that investors for firm $L$ can further speculate on the insiders' trading. According to Theorem 1, the bubble component for firm $U$ is

$$
B^{U}=\mathrm{E}\left[\left(l_{I I}-\frac{Q}{\tau\left(\eta+\eta_{i n} / 2\right)}\right) I_{\left\{l_{I I}>\frac{Q}{\tau\left(\eta+\eta_{i n} / 2\right)}\right\}}\right] .
$$

It is direct to see that $B^{U}$ is strictly lower than the first term in equation (50). And since the other two terms are strictly positive, $B_{L}$ is strictly higher than $B^{U}$.

\subsection{Proof of Proposition 5}

From Proposition 1, the bubble component in Stage I, $B\left(Q_{f}\right)$ is strictly larger than the bubble component in Stage III, $B(\bar{Q})$. From the proof of Proposition 4, the bubble component in Stage II is larger than that of a hypothetical firm with a share supply of $Q_{f}+Q_{i n}$ and a risk-bearing capacity of $\eta+\eta_{i n} / 2$ for each of the two groups of investors, but without insider selling. Thus, $B_{I I}$ should also be larger than $B(\bar{Q})$ which is determined with an even larger asset supply and a smaller investor risk-bearing capacity.

From Proposition 3, the share turnover and return volatility in the basic model of Section 3 are both decreasing with the asset supply. Thus, the turnover and volatility in Stage III are lower than the turnover and volatility in Stage I due to the increased floating shares.

From our discussion in Subsection 4.2.2, the share turnover from (II, 0) to (II, 1) is always at the maximum level of $1 / 2$, due to the increased speculation among investors regarding the insiders' selling at (II, 2). Thus, share turnover in Stage II is larger than that in Stage III. 
To discuss price volatility from (II, 0 ) to (II, 1 ), we rewrite $p_{I I, 1}$ in equation (46) as

$$
p_{I I, 1}=D_{I}+v_{I I I}-\frac{Q_{f}+Q_{i n}}{\tau\left(2 \eta+\eta_{i n}\right)}+\frac{\hat{D}_{I I}^{A}+\hat{D}_{I I}^{B}}{2}+F\left(l_{I I}\right)
$$

with

$$
F\left(l_{I I}\right)= \begin{cases}-\frac{l_{I}}{2}-\frac{1}{\tau}\left[\frac{1}{\eta+\eta_{i n}}-\frac{1}{2 \eta+\eta_{i n}}\right]\left(Q_{f}+Q_{i n}\right) & \text { if } l_{I I}<-\frac{Q_{f}+Q_{i n}}{\tau\left(\eta+\eta_{i n}\right)} \\ -\frac{\eta_{i n}}{2\left(2 \eta+\eta_{i n}\right)} l_{I I} & \text { if }-\frac{Q_{f}+Q_{i n}}{\tau\left(\eta+\eta_{i n}\right)}<l_{I I}<0 \\ \frac{\eta_{i n}}{2\left(2 \eta+\eta_{i n}\right)} l_{I I} & \text { if } 0<l_{I I}<\frac{Q_{f}+Q_{i n}}{\tau\left(\eta+\eta_{i n}\right)} \\ \frac{l_{I I}}{2}-\frac{1}{\tau}\left[\frac{1}{\eta+\eta_{i n}}-\frac{1}{2 \eta+\eta_{i n}}\right]\left(Q_{f}+Q_{i n}\right) & \text { if } l_{I I}>\frac{Q_{f}+Q_{i n}}{\tau\left(\eta+\eta_{i n}\right)}\end{cases}
$$

Thus, $\operatorname{Var}\left[p_{I I, 1}-p_{I I, 0}\right]=\operatorname{Var}\left[\left(\hat{D}_{I I}^{A}+\hat{D}_{I I}^{B}\right) / 2\right]+\operatorname{Var}\left[F\left(l_{I I}\right)\right]$. While the price volatility in Stage III can be determined in the same as given in the proof of Proposition 3, or more specifically as in equation (A17) by replacing $Q=\bar{Q}$ and $l_{1}=l_{I I I}$. Both functions $F$ and $G$ are monotonically increasing, and symmetric around 0, i.e., $F(l)=-F(-l)$ and $G(l)=-G(-l)$. It is important to note that the function $F$ is more spread out than the function $G$ : $F(l)>G(l), \forall l>0$ and $F(l)<G(l), \forall l<0$. Since $l_{I I}$ and $l_{I I I}$ have the same variance, $\operatorname{Var}\left[F\left(l_{I I}\right)\right]>\operatorname{Var}\left[G\left(l_{I I I}\right)\right]$. Thus, the price volatility in Stage II is larger than the price volatility in Stage III.

\subsection{Proof of Proposition 6}

Let $o \in\{A, B\}$ be the optimistic group at (II, 1), i.e., $\hat{D}_{I I}^{o} \geq \hat{D}_{I I}^{\bar{o}}$. By directly comparing beliefs in equations (31) and (32), we have that $s_{I I}^{o} \geq s_{I I}^{o}$. Given that $s_{I I}^{o}>\bar{D}$, we can show that $\hat{D}_{I I}^{i n}<\hat{D}_{I I}^{o}$ :

$$
\begin{aligned}
\hat{D}_{I I}^{o}-\hat{D}_{I I}^{i n} & =\tau_{\epsilon}\left(\frac{\phi}{\tau}-\frac{1}{\tau_{0}+2 \tau_{\epsilon}}\right)\left(s_{I I}^{o}-\bar{D}\right)+\tau_{\epsilon}\left(\frac{1}{\tau}-\frac{1}{\tau_{0}+2 \tau_{\epsilon}}\right)\left(s_{I I}^{\bar{o}}-\bar{D}\right) \\
& \geq \tau_{\epsilon}\left(\frac{\phi}{\tau}-\frac{1}{\tau_{0}+2 \tau_{\epsilon}}\right)\left(s_{I I}^{o}-\bar{D}\right)+\tau_{\epsilon}\left(\frac{1}{\tau}-\frac{1}{\tau_{0}+2 \tau_{\epsilon}}\right)\left(s_{I I}^{o}-\bar{D}\right) \\
& =\frac{(\phi-1) \tau_{0} \tau_{\epsilon}}{\tau\left(\tau_{0}+2 \tau_{\epsilon}\right)}\left(s_{I I}^{o}-\bar{D}\right)>0
\end{aligned}
$$

where the first inequality is due to the fact that $\frac{1}{\tau}<\frac{1}{\tau_{0}+2 \tau_{\epsilon}}$ and $s_{I I}^{o}>s_{I I}^{\bar{o}}$. 
The stock price on (II, 1) is determined by the market clearing condition for period (II, 2) in the group-o investors' mind, who think that insiders share their belief when they start to trade at (II, 2):

$$
\begin{aligned}
& \eta^{i n} \tau \max \left(D_{I}+v_{I I I}+\hat{D}_{I I}^{o}-p_{I I, 1}, 0\right)+\eta \tau \max \left(D_{I}+v_{I I I}+\hat{D}_{I I}^{o}-p_{I I, 1}, 0\right) \\
& +\eta \tau \max \left(D_{I}+v_{I I I}+\hat{D}_{I I}^{\bar{o}}-p_{I I, 1}, 0\right)=Q_{f}+Q_{i n}
\end{aligned}
$$

The stock price on (II, 2) is determined by the actual market clearing at that time when insiders start to trade based on their actual belief:

$$
\begin{aligned}
& \eta^{i n}\left(\tau_{0}+2 \tau_{\epsilon}\right) \max \left(D_{I}+v_{I I I}+\hat{D}_{I I}^{i n}-p_{I I, 2}, 0\right)+\eta \tau \max \left(D_{I}+v_{I I I}+\hat{D}_{I I}^{o}-p_{I I, 2}, 0\right) \\
& +\eta \tau \max \left(D_{I}+v_{I I I}+\hat{D}_{I I}^{\bar{o}}-p_{I I, 2}, 0\right)=Q_{f}+Q_{i n}
\end{aligned}
$$

Note that equations (A26) and (A27) are strictly decreasing with $p_{I I, 1}$ and $p_{I I, 2}$, respectively. Since $\tau_{0}+2 \tau_{\epsilon}<\tau$ and $\hat{D}_{I I}^{i n}<\hat{D}_{I I}^{o}$, equations (A26) and (A27) imply that $p_{I I, 2}<p_{I I, 1}$. 


\section{References}

[1] Allen, Franklin and Gary Gorton (1993), Churning bubbles, Review of Economic Studies 60, 813-836.

[2] Allen, Franklin, Stephen Morris, and Andrew Postlewaite (1993), Finite bubbles with short sale constraints and asymmetric information, Journal of Economic Theory 61, 206-229.

[3] Almazan, A., Brown, Beth C., Carlson, Murray and Chapman, David A. (2001), Why Constrain Your Mutual Fund Manager? University of Texas Working Paper.

[4] Alpert, Marc and Howard Raiffa (1982), A progress report on the training of probability assessors, in Daniel Kahneman, Paul Slovic, and Amos Tversky, ed.: Judgement under Uncertainty: Heuristics and Biases, Cambridge University Press, Cambridge.

[5] Barber, Brad and Terrance Odean (2001), The internet and the investor, Journal of Economic Perspectives 15, 41-54.

[6] Bernardo, Antonio, and Ivo Welch (2001), On the evolution of overconfidence and entrepreneurs, Journal of Economics and Management Strategy 10, 301-330.

[7] Blanchard, Olivier and Mark Watson (1982), Bubbles, rational expectations and financial markets, in P. Wachtel (ed.) Crisis in the Economic and Financial Structure: Bubbles, Bursts, and Shocks, Lexington Press, Lexington, MA.

[8] Brav, Alon and Paul A. Gompers (2003), The role of lockups in initial public offerings, Review of Financial Studies 16, 1-29.

[9] Camerer, C. (1995), Individual decision making, in John Kagel and Alvin Roth (ed.) The Handbook of Experimental Economics, Princeton University Press, Princeton, NJ.

[10] Chen, Joseph, Harrison Hong and Jeremy Stein (2002), Breadth of ownership and stock returns, Journal of Financial Economics 66, 171-205.

[11] Cochrane, John (2002), Stocks as money: convenience yield and the tech-stock bubble, NBER Working Paper 8987.

[12] Daniel, Kent, David Hirshleifer, and A. Subrahmanyam (1998), Investor psychology and security market under- and overreaction, Journal of Finance 53, 1839-1885.

[13] DeGroot, M.H. (1970), Optimal Statistical Decisions. McGrawhill, New York.

[14] Duffie, Darrell, Nicolae Garleanu and Lasse Pedersen (2002), Securities lending, shorting, and pricing, Journal of Financial Economics 66, 307-339.

[15] Field, Laura Casares and Gordon Hanka (2001), The expiration of IPO share lockups, Journal of Finance 56, 471-500.

[16] Harris, Milton and Artur Raviv (1993), Differences of opinion make a horse race, Review of Financial Studies 6, 473-506.

[17] Harrison, Michael and David Kreps (1978), Speculative investor behavior in a stock market with heterogeneous expectations, Quarterly Journal of Economics 92, 323-336.

[18] Hirshleifer, David (2001), Investor psychology and asset pricing, Journal of Finance 56, 15331597. 
000333880

\section{||||||||||||||||||||||||||||||||||||}

N.Cham. P/EPGE SPE H772a

Autor: Hong, Harrison

Título: Asset float and speculative bubbles.

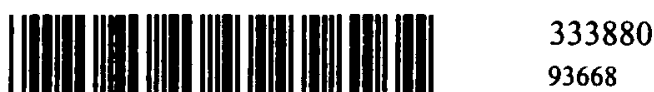

93668

FGV - BMHS

$\mathrm{N}^{\circ}$ Pat. 333880 
[19] Hong, Harrison and Jeremy Stein (2003), Differences of opinion, short-sales constraints and market crashes, Review of Financial Studies 16, 487-525.

[20] Kandel, Eugene and Neil Pearson (1995), Differential interpretation of public signals and trade in speculative markets, Journal of Political Economy 103, 831-872.

[21] Koski, Jennifer Lynch and Pontiff, Jeffrey (1999), How Are Derivatives Used? Evidence from the Mutual Fund Industry, Journal of Finance, 54, 791-816.

[22] Kyle, Albert and Tao Lin (2002), Continuous speculation with overconfident competitors, Working paper, Duke University.

[23] Kyle, Albert and Albert Wang (1997), Speculation duopoly with agreement to disagree: Can overconfidence survive the market test? Journal of Finance 52, 2073-2090.

[24] Lamont, Owen and Richard Thaler (2003), Can the market add and subtract? Mispricing in tech stock carve-outs, Journal of Political Economy 111, 227-268.

[25] Lichtenstein, S., B. Fischhoff, and L. Phillips (1982), Calibration of probabilities: The state of the art to 1980, in Daniel Kahneman, Paul Slovic, and Amos Tversky, ed.: Judgement under Uncertainty: Heuristics and Biases, Cambridge University Press, Cambridge.

[26] Lord, C. G., L. Ross, and M. R. Lepper (1979), Biased assimilation and attitude polarization: The effects of prior theories on subsequently considered evidence, Journal of Personality and Social Psychology 37, 2098-2109.

[27] Miller, Edward (1977), Risk, uncertainty and divergence of opinion, Journal of Finance 32, 1151-1168.

[28] Mitchell, Mark, Todd Pulvino, and Erik Stafford (2002), Limited arbitrage in equity markets, Journal of Finance, 551-584.

[29] Morris, Stephen (1996), Speculative investor behavior and learning, Quarterly Journal of Economics 110, 1111-1133.

[30] Odean, Terrance (1998), Volume, volatility, price, and profit when all traders are above average, Journal of Finance 53, 1887-1934.

[31] Ofek, Eli and Matthew Richardson (2000), The IPO lock-up period: Implications for market efficiency and downward sloping demand curves, NYU Working Paper.

[32] Ofek, Eli and Matthew Richardson (2003), Dotcom mania: The rise and fall of internet stock prices, Journal of Finance 58, 1113-1137.

[33] Santos, Manuel, and Michael Woodford (1997), Rational asset pricing bubbles, Econometrica $65,19-57$.

[34] Scheinkman, Jose and Wei Xiong (2003), Overconfidence and speculative bubbles, Journal of Political Economy, forthcoming.

[35] Shleifer, Andrei and Robert Vishny (1997), Limits of arbitrage, Journal of Finance 52, 35-55.

93668

BIBLIOTECA

MAR!O HENRIQUE SIMOANSEN

FUNDACAO GETULLIO VARECO

$\frac{333880}{17 / 02 / 2004}$

